\title{
Central Nervous System Remyelination: Roles of Glia and Innate Immune Cells
}

\author{
Charbel S. Baaklini ${ }^{1}$, Khalil S. Rawji ${ }^{2}$, Greg J. Duncan ${ }^{3}$, Madelene F. S. Ho ${ }^{1}$ \\ and Jason R. Plemel ${ }^{1 *}$
}

\begin{abstract}
'Department of Medicine, Division of Neurology, Neuroscience and Mental Health Institute, Faculty of Medicine \& Dentistry, University of Alberta, Edmonton, AB, Canada, ${ }^{2}$ Wellcome Trust-Medical Research Council, Cambridge Stem Cell Institute, Cambridge Biomedical Campus, University of Cambridge, Cambridge, United Kingdom, ${ }^{3}$ Department of Neurology, Jungers Center for Neurosciences Research, Oregon Health and Science University, Portland, OR, United States
\end{abstract}

\section{OPEN ACCESS}

Edited by:

Craig Stephen Moore Memorial University of Newfoundland, Canada

Reviewed by: Andrew David Greenhalgh, INRA UMR1286 Laboratoire

NutriNeuro, France

Samaneh Maysami,

University of Manchester. United Kingdom

${ }^{*}$ Correspondence: Jason R. Plemel jrplemel@ualberta.ca

Received: 28 June 2019 Accepted: 04 September 2019 Published: 19 September 2019

Citation: Baaklini CS, Rawji KS, Duncan GJ, Ho MFS and Plemel JR (2019) Central Nervous System

Remyelination: Roles of Glia and Innate Immune Cells.

Front. Mol. Neurosci. 12:225. doi: 10.3389/fnmol.2019.00225
In diseases such as multiple sclerosis (MS), inflammation can injure the myelin sheath that surrounds axons, a process known as demyelination. The spontaneous regeneration of myelin, called remyelination, is associated with restoration of function and prevention of axonal degeneration. Boosting remyelination with therapeutic intervention is a promising new approach that is currently being tested in several clinical trials. The endogenous regulation of remyelination is highly dependent on the immune response. In this review article, we highlight the cell biology of remyelination and its regulation by innate immune cells. For the purpose of this review, we discuss the roles of microglia, and also astrocytes and oligodendrocyte progenitor cells (OPCs) as they are being increasingly recognized to have immune cell functions.

Keywords: remyelination, microglia, oligodendrocyte, oligodendrocyte progenitor cells, astrocytes, white matter disease, aging

\section{INTRODUCTION}

Demyelination is a common feature of disease occurring after conditions such as spinal cord injury (SCI; Crowe et al., 1997; Powers et al., 2012; Plemel et al., 2014), multiple sclerosis (MS; Franklin and Ffrench-Constant, 2008; Plemel et al., 2017), stroke (Rosenzweig and Carmichael, 2015; Khodanovich et al., 2018), and traumatic brain injury (Mierzwa et al., 2015; Armstrong et al., 2016). Moreover, white matter loss occurs in Alzheimer's disease (Mitew et al., 2010; Carmeli et al., 2013; Zhan et al., 2014; Bejanin et al., 2017) and is a feature of aging that is correlated with cognitive decline (Bartzokis et al., 2012; Yeatman et al., 2014; Li et al., 2017). With age, myelin shows increasing signs of damage while at the same time myelin debris accumulates within microglia (Safaiyan et al., 2016; Hill et al., 2018), which can trigger cholesterol crystal formation and inflammasome activation (Cantuti-Castelvetri et al., 2018). In MS, more remyelination is associated with less disability (Bramow et al., 2010; Bodini et al., 2016), suggesting that enhancing remyelination is a viable therapeutic strategy that is only recently showing benefits in clinical trials (Plemel et al., 2017). However, for those with MS, remyelination is variable and prone to failure (Prineas et al., 1993; Patrikios et al., 2006; Patani et al., 2007; Bramow et al., 2010), especially in the context of aging which is known to slow the rate of remyelination (Shields et al., 1999; Goldschmidt et al., 2009; Ruckh et al., 2012; Brown et al., 2014; Frischer et al., 2015). In this review article, we focus on the innate immune cells of the central nervous system (CNS) and their role during remyelination. We include microglia as the primary CNS innate immune cells, but also recognize that other glia such as astrocytes and oligodendrocyte progenitor cells (OPCs) may sculpt the innate immune response. 


\section{CELL BIOLOGY OF REMYELINATION}

\section{Importance of Remyelination}

Demyelination, or the loss of myelin, can be induced due to injury or disease. MS is characterized by inflammatory demyelination, possibly induced by monocytes, macrophage/microglia, and T-cells. For example, microglia/macrophage-derived oxidative species cause damage by inducing myelin and axonal injury (Haider et al., 2011; Nikic et al., 2011; Witte et al., 2019). The immune system produces demyelination by many other mechanisms, but this is not the focus of this review (Mayo et al., 2012; Lassmann and van Horssen, 2016; Mishra and Yong, 2016; Davies and Miron, 2018). Demyelination slows axonal conduction, and as suggested by computer simulations (Koles and Rasminsky, 1972; Waxman and Brill, 1978), may even result in a failure to propagate the signal past the demyelinated segment (Koles and Rasminsky, 1972; Waxman and Brill, 1978). The conduction block associated with demyelination is thought to relate to ionic disbalance once the myelin is removed. The loss of myelin unmasks potassium channels underneath the myelin sheath that can act as a current sink (Schauf and Davis, 1974; Bostock et al., 1978, 1981; Sherratt et al., 1980; Wang et al., 1993, 1995). To compensate, axons can upregulate voltage-gated sodium channels along their length (Foster et al., 1980; England et al., 1991; Black et al., 2007; Hamada and Kole, 2015). Potentially due to this upregulation or redistribution of voltage-gated sodium channels, it is possible to propagate the signal along a demyelinated segment, albeit more slowly (Felts et al., 1997). Associated with the axonal conduction block is a corresponding functional loss or alteration. For example, demyelination of the ventral medial geniculate nucleus (vMGN) or A1 region in the auditory cortex in mice results in both impaired sound frequency-specific responses and an increase in latency in auditory responses (Narayanan et al., 2018). Importantly, while remyelination may speed axonal propagation, it is not always linked to functional recovery (Duncan et al., 2009, 2018; Mozafari et al., 2010; Assinck et al., 2017a; Narayanan et al., 2018). Both the extent and severity of demyelination may dictate the functional consequences. For example, in an experimental murine model of SCI where demyelination is confined to the lesion, preventing remyelination did not change the spontaneous recovery, potentially because after SCI conduction is not sufficiently disrupted (Felts et al., 1997; Duncan et al., 2017, 2018).

Remyelination also maintains axonal integrity and attenuates axonal degeneration. If remyelination is slowed using irradiation to ablate OPCs in mice, there is more axonal degeneration (Irvine and Blakemore, 2008). However, this study is confounded by off-target effects of irradiation including blood-brain barrier (BBB) disruption (Diserbo et al., 2002), enhanced astrogliosis (Wilson et al., 2009), and activation of microglia (Hwang et al., 2006; Irvine and Blakemore, 2008). More specifically, if remyelination is accelerated by promoting oligodendrocyte differentiation in a cell-type specific manner, more axons are preserved (Mei et al., 2016). How might myelin protect axons? One likely mechanism is via the buffering of potassium through the potassium channel KIR4.1, expressed in oligodendrocytes
(Schirmer et al., 2018). Potassium is released from axons as part of their action potential and conditional oligodendrocyte-specific removal of this KIR4.1 buffering results in late-onset axonal degeneration, suggesting that myelinic potassium buffering maintains axonal integrity. Oligodendrocytes also support axons by providing them with glycolytic metabolites via the myelin sheath (Fünfschilling et al., 2012; Saab et al., 2016; Micu et al., 2017). Even the myelin sheath may itself can act as a protective barrier by surrounding the axon from toxic reactive oxygen species (Nikic et al., 2011; Witte et al., 2019). The myelin sheath also shifts some of the metabolic demands from the axon to the oligodendrocyte. For example, when an axon is myelinated there is less sodium released for an axon potential, and therefore less energy is required to repolarize its membrane, yet the production of myelin is energetically expensive (Harris and Attwell, 2012). Other possible mechanisms of axonal support by oligodendrocytes include the release of oligodendrocyte-derived exosomes or ribosomes (Frühbeis et al., 2013; Shakhbazau et al., 2016). Oligodendrocytes can also secrete many other factors to boost neuronal health or survival in culture such as insulin-like growth factor 1 (IGF-1) and glial cell-derived neurotrophic factor (GDNF; Wilkins et al., 2001, 2003; Dai et al., 2003), which may support axons in vivo.

An analogous relationship between glial cells and axons exists in the peripheral nervous system (PNS). Schwann cells (SCs) are glial cells generally restricted to the PNS that arise from neural crest-derived SC precursors (Monk et al., 2015). Under normal conditions, SCs myelinate axons in the PNS. However, there is evidence that SCs can remyelinate in the CNS under inflammatory conditions. In fact, $\mathrm{P}_{0}$ staining-a marker for SC-derived myelin sheaths-was observed in MS spinal cord lesions (Itoyama et al., 1983). Indeed, fate-mapping revealed that in LPC-demyelinated lesions, PDGFRa and NG2-expressing progenitor cells in the CNS produce the myelinating oligodendrocytes and SCs (Zawadzka et al., 2010).

\section{Process of Remyelination}

Remyelination is a regenerative process that requires the sequential activation and recruitment of OPCs to areas of demyelination, followed by their differentiation into new oligodendrocytes-but also less frequently into SCs-and subsequent myelin deposition around demyelinated axons (Franklin and Ffrench-Constant, 2008, 2017; Zawadzka et al., 2010; Plemel et al., 2017). OPCs are found throughout the adult mouse brain white matter and gray matter (Dimou et al., 2008; Rivers et al., 2008; Kang et al., 2010). After a demyelinating insult, OPCs transition to a reactive state with the upregulation of key transcription factors such as $\mathrm{Nkx} 2.2$, Olig2 and Sox2 (Levine and Reynolds, 1999; Fancy et al., 2004; Zhao et al., 2015). In the lesion, there is a release of many growth factors such as platelet-derived growth factor (PDGF) and fibroblast growth factor (FGF; Hinks and Franklin, 1999; Messersmith et al., 2000). These factors and others are thought to regulate OPC lineage progression by increasing proliferation and migration towards the lesion (Messersmith et al., 2000; Murtie et al., 2005; Dehghan et al., 2012). OPCs proliferate and migrate in the days following demyelination or injury, as part 
of their recruitment (Redwine and Armstrong, 1998; Hughes et al., 2013). Following OPC recruitment, they differentiate and mature into myelinating oligodendrocytes, which involves the ensheathment and enwrapping of the denuded axon with a new myelin sheath (Tripathi et al., 2010; Zawadzka et al., 2010; Crawford et al., 2016b). Differentiated oligodendrocytes start expressing myelin proteins such as myelin basic protein (MBP), which allows for the compaction of myelin membranes (Kimura et al., 1989; Watanabe et al., 2002; Polito and Reynolds, 2005; Snaidero et al., 2014). Much of the process of oligodendrocyte differentiation is due to key transcription factors. For example, the transcription factor myelin regulatory factor (MyRF) is required for oligodendrocyte maturation and myelination (Emery et al., 2009) and effective remyelination in adulthood (Duncan et al., 2017). MyRF binds to enhancer sequences and directly drives the expression of myelin genes (Bujalka et al., 2013); it is necessary for remyelination after chemical and traumatic demyelinating injuries (Duncan et al., 2017, 2018). Remyelinating oligodendrocytes can adopt different phenotypes, as shown by single-nucleus RNA sequencing (Jäkel et al., 2019). Interestingly, oligodendrocytes in the white matter of MS patients compared to non-diseased controls have different subclustering based on their transcriptomes. This shift in oligodendrocyte phenotypes may reflect an impaired capacity to remyelinate but the functional consequences of these different phenotypes have not yet been directly determined.

Much of the research on remyelination is conducted on demyelinating rodent models. Using these models, it has been shown that OPCs, and not mature oligodendrocytes, are the cells most responsible for remyelination (Crawford et al., 2016a). Transplantation of mature oligodendrocytes into demyelinated lesions do not remyelinate denuded axons (Targett et al., 1996). Oligodendrocyte fate-mapping in mice also demonstrated that mature oligodendrocytes do not engage in remyelination (Crawford et al., 2016a). Surprisingly, new data provides evidence that mature oligodendrocytes can remyelinate in larger mammals. Duncan et al. (2018) find the presence of oligodendrocytes with both thick and thin myelin sheaths using a feline irradiated food-induced demyelination (FIDID) model and vitamin B12 deficiency and in a non-human primate model. Given that remyelination is typically, but not always associated with thin myelin sheaths (Blakemore, 1974; Duncan et al., 2017), one explanation for these results is that spared oligodendrocytes with a thick, unaffected, myelin sheath can re-extend their processes and remyelinate adjacent denuded axons (Duncan et al., 2018). An alternative possibility with this study is that myelin sheath thickness may be differentially regulated by the axon. In a recent study, Yeung et al. (2019) investigated oligodendrogenesis in humans with MS using a specific carbon dating strategy. After cell division, the daughter cell's DNA will have a radioactive carbon concentration that is proportional to concentration of radioactive carbon in the atmosphere. As a result of atomic bomb testing starting in the mid-late 1940s, the atmospheric radioactive carbon increased making it possible to date daughter cells after the 1940s based on the nuclear radioactive carbon levels. Using this strategy, Yeung et al. (2019) measured new oligodendrocyte production in shadow plaques, which are regions of intermediate lipid staining that are thought to be remyelinated. Surprisingly, they found that new oligodendrocyte production was similar in shadow plaques to those found in the non-diseased brain, suggesting that in humans the mature oligodendrocytes can remyelinate denuded axons. However, in this one study, these conclusions are based off of 11 samples. Moreover, this study found that OPCs did turn over in shadow plaques, but due to the levels of atmospheric radioactive carbon, this was only apparent for those born in the mid-1960s onwards. Only one shadow plaque was measured for oligodendrocyte carbon after this critical mid-1960s period. The question of whether adult oligodendrocytes can remyelinate will, therefore, require further validation in future studies.

\section{ROLES OF MICROGLIA AND INFILTRATING MACROPHAGES IN REMYELINATION}

Microglia are immunocompetent glial cells of the CNS (Streit, 2002). They are the CNS parenchymal macrophages that arise developmentally from erythromyeloid precursors in the yolk sac (Ginhoux et al., 2010; Kierdorf et al., 2013). They are unevenly distributed according to the CNS region and range from 5 to $12 \%$ of glia in the mouse brain and $0.5 \%-16.6 \%$ of human brain parenchymal cells (Lawson et al., 1990; Mittelbronn et al., 2001). They are important for controlling many neurodevelopmental processes. For example, neural precursor cells proliferate in the presence of microglia in vitro (Antony et al., 2011). Also, microglia conditioned media promotes the differentiation of neural precursor cells into neurons as well as astrocytes (Nakanishi et al., 2007; Antony et al., 2011). Microglial ablation results in neuronal apoptosis and a decrease in spine density in young mice indicating microglia promote synaptogenesis and the survival of neurons (Ueno et al., 2013; Miyamoto et al., 2016). Microglia also regulate myelinogenesis through the secretion of growth factors like IGF-1, which is critical for $M b p$ expression in young mice (Wlodarczyk et al., 2017).

\section{Microglia Response to Injury}

Microglia regulate homeostasis by surveying their microenvironment but are highly responsive to injury or disease as laser-induced injury in the mouse neocortex results in microglial extensions surrounding the site of injury (Davalos et al., 2005; Nimmerjahn et al., 2005). When there is more damage over a longer period of time, for example following focal demyelination with LPC, microglia can retract their processes and become more spheroidal (Plemel et al., 2018). These morphological attributes of activated microglia, as well as similar expression patterns, have made it difficult to differentiate microglia from other macrophages such as border-associated macrophages in the CNS that include meningeal, choroid plexus and perivascular macrophages (Goldmann et al., 2016; Mrdjen et al., 2018), as well as monocyte-derived macrophages (Butovsky et al., 2014). Most studies do not differentiate between these cell types. As such, in this review article, these cells will be referred to as microglia/macrophages.

Microglia are surveillant cells that are highly responsive to environmental cues. In adults, microglia self-renew with modest 
proliferation (Nimmerjahn et al., 2005; Elmore et al., 2014; Kawabori and Yenari, 2015). In the uninjured state of the CNS, in vivo imaging revealed that ramified microglia continuously scan their microenvironment by undergoing structural changes including filopodia extension and retraction (Nimmerjahn et al., 2005; Bernier et al., 2019). By this surveillance mechanism, using two-photon microscopy of living murine microglia, Davalos et al. (2005) demonstrate that they detect and act accordingly to damage-associated molecular patterns (DAMPs). Microglia respond to disease conditions through a combination of receptors such as pattern recognition receptors, purinergic and fractalkine receptors, and cytokine receptors (Hickman et al., 2013). Microglia likely responds to hundreds, if not thousands of molecules, many in undefined ways. Certain molecules elicit specific responses, for example, the subsequent activation of purinergic receptors leads to the activation of the phagocytic pathway in rat microglia, that involves the clearance of apoptotic cells, both in vitro and in vivo (Davalos et al., 2005; Haynes et al., 2006; Koizumi et al., 2007; Bernier et al., 2019).

\section{Microglia During Remyelination}

In the context of remyelination, microglia/macrophages can have many beneficial roles. However, these cells also contribute to autoimmune-related toxicity (Heppner et al., 2005; Ajami et al., 2011; Goldmann et al., 2013; Rothhammer et al., 2018). The dichotomous nature of microglia and macrophages is incompletely understood. One important function of microglia/macrophages following demyelination is the removal of inhibitory myelin debris present in the lesion. This myelin debris has been shown to negatively regulate OPC lineage progression (Syed et al., 2008; Plemel et al., 2013) and consequently, remyelination (Kotter et al., 2006). As microglia are phagocytotic cells, they contribute to myelin debris clearance (Sosa et al., 2013; Rawji et al., 2018). This phagocytosis is reflected by the presence of myelin proteins such as MBP in microglia/macrophages in the white matter following demyelination (Sosa et al., 2013).

Microglia also secrete an array of signaling molecules, including cytokines, chemokines and growth factors; many of these factors signal via receptors on oligodendrocyte lineage cells. For instance, the proinflammatory cytokine tumor necrosis factor- $\alpha$ (TNF- $\alpha)$, secreted by microglia/macrophages as well as astrocytes in mouse cuprizone-induced lesions, promotes OPC expansion and remyelination through TNF receptor 2 (TNFR2) on NG2 ${ }^{+}$cells (Arnett et al., 2001; Voss et al., 2012). Interleukin-1 $\beta$ (IL-1 $\beta$ ), also secreted by microglia/macrophages and astrocytes, is important for remyelination potentially by controlling oligodendrocyte lineage cell's survival by stimulating IGF-1 secretion from microglia/macrophages in cuprizone-treated mice (Mason et al., 2001). Recently, it was shown microglia can modulate remyelination through the secreted enzyme transglutaminase 2 (TG2). TG2 interacts with OPC-specific Adhesion G Protein-Coupled Receptor G1 (ADGRG1) to promote OPC proliferation. Either, microgliaspecific loss of TG2 or OPC-specific loss of ADGRG1 impairs remyelination in two murine demyelination models (Giera et al., 2018). As microglia/macrophages transition from a more pro-inflammatory state in the days after demyelination to a more immunoregulatory phenotype at a later time point, they secrete Activin-A in mouse lesions (Miron et al., 2013). Activin-A release, in turn, interacts with activin receptors on OPCs, which are required for developmental myelination and remyelination (Dillenburg et al., 2018).

It is important to note that some of the cytokines that have pro-remyelinating roles can be implicated in mediating pathogenesis, including, for example, TNF- $\alpha$ that is required for autoimmune demyelination (Ruddle et al., 1990; Selmaj et al., 1991; Baker et al., 1994; Steeland et al., 2017). In addition, IL-1 $\beta$ from neutrophils and monocyte-derived macrophages drives neuroinflammation in EAE mice (Lévesque et al., 2016; Paré et al., 2018). Indeed, in autoimmune demyelination the removal of a key NF-kB regulator, TAK1, from microglia and CNS macrophages prevents EAE, suggesting an important role of these cells in the execution of autoimmune demyelination (Goldmann et al., 2013).

\section{Microglia Response Is Heterogeneous}

Recent transcriptomic analyses in both mice and humans revealed that the microglia response to acute demyelination is more heterogeneous than previously thought (Hammond et al., 2019; Masuda et al., 2019). In the resting state, microglia typically adopt a homeostatic phenotype characterized by the expression of such markers as CX3CR1, the purinergic receptor P2RY12, and TMEM119 (Krasemann et al., 2017; Masuda et al., 2019). As microglia become activated, they shift their phenotype. One recently characterized microglia phenotype is the damageassociated microglia (DAM), which are a subset of microglia revealed by single-cell RNA sequencing in Alzheimer's Disease transgenic mice (Keren-Shaul et al., 2017). DAM are linked to neurodegeneration and are characterized by the upregulation TREM2, a phagocytic marker (Deczkowska et al., 2018). Many of these markers associated with DAM are also upregulated in microglia following demyelination such as Lpl, Cst7 and Apoe, suggesting that there is an overlapping response between neurodegeneration and demyelination (Keren-Shaul et al., 2017; Hammond et al., 2019). The transition to a less pro-inflammatory microglia/macrophage phenotype is promoted by the secreted enzyme, interleukin 4 induced 1 , which is induced in microglia in response to interleukin 4 (Psachoulia et al., 2016). Recently, it was shown that necroptosis of microglia/macrophages is important in the phenotypic shift during remyelination, suggesting that microglia/macrophages may not transition between phenotypes but instead die, only to be replaced by alternative phenotypes (Lloyd et al., 2019).

\section{Infiltrating Macrophages During Remyelination}

The functional overlap of monocytes-derived macrophages and microglia during remyelination is still unclear. Monocytederived macrophages are mononuclear phagocytic cells of the hematopoeitic stem cell lineage (Jakubzick et al., 2017). Under inflammatory conditions in the CNS, circulating monocytes cross the $\mathrm{BBB}$ and mature into macrophages (King et al., 2009; Caravagna et al., 2018). These infiltrating macrophages 
are evident in both MS lesions and in the different models of demyelination/remyelination such as EAE, LPC and cuprizonetreated animal models (Hiremath et al., 1998; Trebst et al., 2001; King et al., 2009; Miron et al., 2013; Vogel et al., 2013; Kuhlmann et al., 2017). Monocytes that express C-C Motif Chemokine Receptor (CCR2), known as inflammatory monocytes, migrate into the CNS in response to $\mathrm{C}$-C Motif Chemokine Ligand 2 (CCL2). Following cuprizone toxicity or in aged mice following focal demyelination, the vast majority of monocytes require CCR2 for their entry (Ruckh et al., 2012; Lampron et al., 2015). CCR2-knockout mice are resistant to EAE (Fife et al., 2000) and blocking monocyte infiltration prevents EAE in mice (Ajami et al., 2011) suggesting that monocytes are required for autoimmune-mediated demyelination in part by the production of reactive oxygen species (Nikic et al., 2011; Locatelli et al., 2018).

The roles of monocyte-derived macrophages are just beginning to be characterized during remyelination and can be difficult to delineate from microglia as experimentally manipulating these cells while leaving the microglial response intact is challenging. During remyelination, the early use of clodronate liposomes reduces remyelination. Clodronate liposomes are artificial lipid vesicles that are taken up preferentially by phagocytic cells and kill circulating monocytes and macrophages (van Rooijen, 1992; Van Rooijen and Sanders, 1994; Popovich et al., 1999; Kotter et al., 2006; Döring et al., 2015), but they can also ablate microglia (Kumamaru et al., 2012; Han et al., 2019). It is, therefore, still unclear whether clodronate liposomes impair remyelination by killing microglia or macrophages or both. One important correlate of remyelination is the removal of inhibitory myelin debris for which young monocyte-derived macrophages participate (Ruckh et al., 2012). However, it is still unclear whether microglia or macrophages predominate during myelin debris phagocytosis. Taken together, CNS-infiltrating macrophages promote demyelination, but the overlap in functions between microglia and macrophages during remyelination is less clear.

Taken together, microglia and macrophage likely possess overlapping functions that are not completely defined, which as a whole are required for remyelination (Figure 1). One critical function is the phagocytosis of inhibitory myelin debris, but other key roles of these cells include secretion of growth factors and the regulation of the immune response through cytokines and other immunoregulatory molecules. The response of these cells is heterogeneous and exciting new technologies such as single-cell RNA sequencing will allow for the characterization of their response during the continuum of remyelination.

\section{ROLES OF OTHER INNATE IMMUNE CELLS DURING REMYELINATION}

Following demyelination microglia/macrophages predominate, but other innate immune cells could potentially participate in remyelination. The other cells of the innate immune system include natural killer cells, mast cells, eosinophils, basophils, neutrophils, and dendritic cells. Many of these innate immune cells can inflict tissue damage (Mayo et al., 2012; Boutajangout and Wisniewski, 2013; Courties et al., 2014), but little is known about their role in remyelination. In the context of demyelinating diseases, several of these innate immune cells have a described role during demyelination. For instance, neutrophils are important players in disease pathogenesis as mice lacking the key neutrophils chemokine receptor, C-X-C motif chemokine receptor 2 (CXCR2), are resistant to cuprizoneinduced oligodendrocyte cell death and demyelination (Liu et al., 2010). Eosinophils also contribute to demyelination as preventing their infiltration into the CNS in EAE mice decreases disease severity (Gladue et al., 1996). Mast cells, which are found in MS lesions, are also important in disease pathogenesis as blocking their ability to degranulate in EAE rats reduces disease severity (Olsson, 1974; Dimitriadou et al., 2000). To date, less is known about how eosinophils, basophils and neutrophils regulate remyelination. Dendritic cells, which are professional antigen producing cells, may have pro-remyelinating roles (Pusic et al., 2014). Dendritic cells challenged with interferon $\gamma$ (IFN $\gamma$ ) release exosomes containing microRNA such as miR-219. These dendritic cell-derived exosomes improve remyelination in cultured rat hippocampal slices ex vivo, however, it is still unclear how dendritic cells regulate remyelination in vivo. Given the complex interplay between various innate immune cells and their known involvement in repair of other systems, such as during wound healing (MacLeod and Mansbridge, 2016), there are likely other unknown roles for these cells during remyelination.

\section{ROLES OF ASTROCYTES IN REMYELINATION}

Astrocytes have important roles in both CNS development and homeostasis such as during synaptogenesis, neurotransmission, BBB formation and maintenance, among other roles (Sofroniew and Vinters, 2010; Molofsky and Deneen, 2015). In response to neuroinflammation, astrocytes respond in a process called reactive astrogliosis (Zamanian et al., 2012). Reactive astrocytes have both potentially beneficial and detrimental roles during remyelination; indeed, these functions may relate to a particular phenotype that the astrocytes adopt (Liddelow and Barres, 2017; Liddelow et al., 2017). Astrocytes may promote/inhibit remyelination directly, but could also signal through microglia to promote remyelination. For example, the ablation of reactive astrocytes in cuprizone-treated mice impairs recruitment of microglia to the demyelinating lesion (Skripuletz et al., 2013). Lowered microglia recruitment is associated with reduced clearance of inhibitory myelin debris, which impairs oligodendrocyte maturation (Syed et al., 2008; Plemel et al., 2013) and remyelination (Kotter et al., 2006). The inverse is likely also true, whereby microglia can regulate astrocyte function. Microglia activated by a TLR4 agonist, LPS, induces a newly identified neurotoxic phenotype of astrocytes. The neurotoxic astrocyte may be detrimental for OPC maturation as it has been shown to induce oligodendrocyte and neuronal apoptosis (Liddelow et al., 2017). As microglia/macrophages display a temporal shift from a predominantly pro-inflammatory phenotype to an 


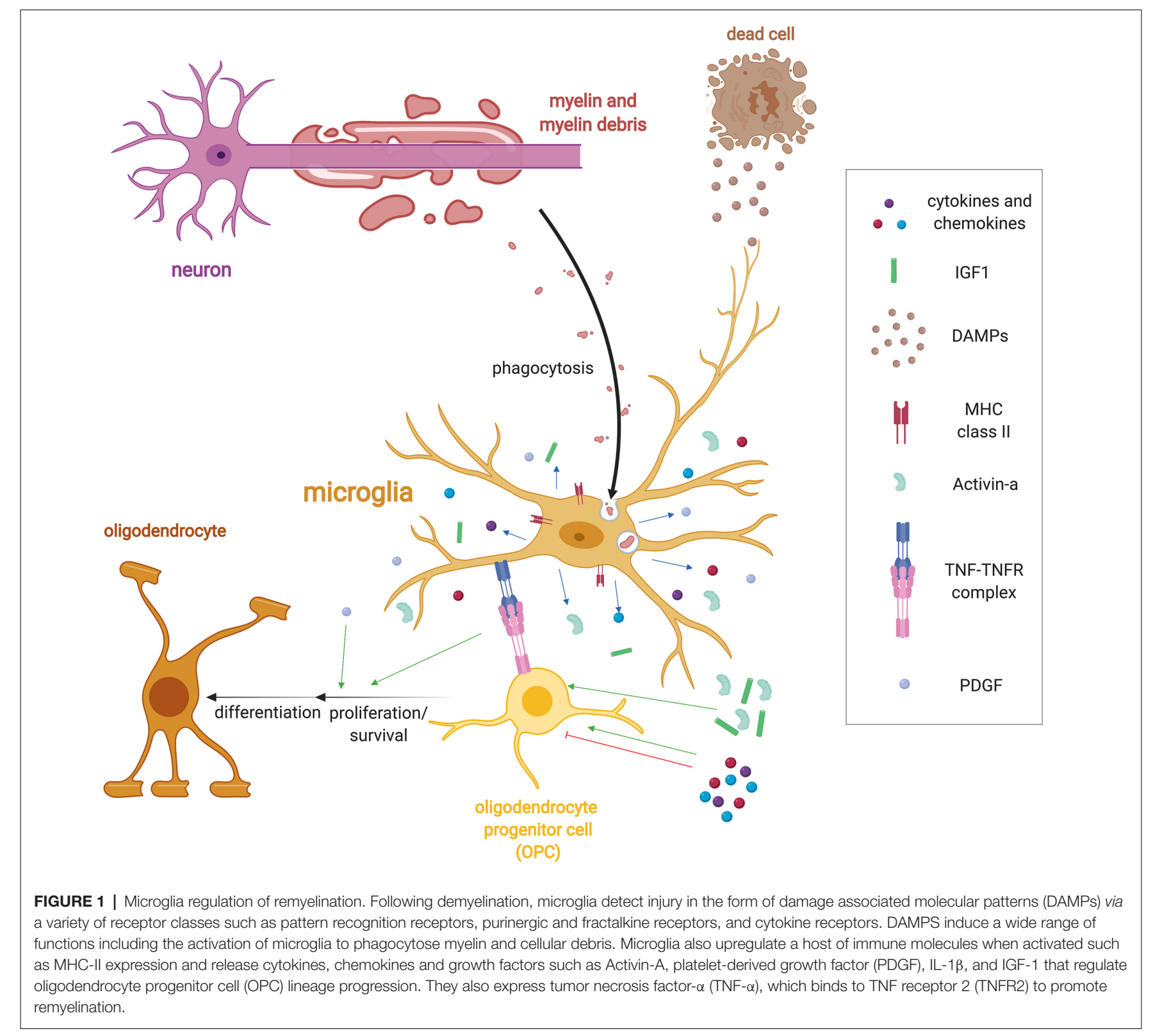

anti-inflammatory phenotype (Miron et al., 2013), it is unknown whether the astrocytes within a demyelinating lesion adopt a similar temporal shift in phenotype and whether this may in turn yield a spectrum of beneficial or detrimental functions for remyelination.

One role of astrocytes is mediated by endothelin-1, a peptide that has been characterized to potently induce vasoconstriction. Following demyelination in animal models and in MS patients' lesions, astrocytes begin expressing endothelin-1 (ET-1; Hammond et al., 2014). ET-1 is secreted by astrocytes and endothelial cells and acts in paracrine and autocrine manners in the CNS (Hostenbach et al., 2016). ET-1 can activate receptors on vascular smooth muscle cells, inducing vasoconstriction and leading to cerebral hypoperfusion, which is commonly observed in MS patients (Law et al., 2004; Varga et al., 2009). Low oxygen tension, at least during development in mice, also impairs OPC maturation (Yuen et al., 2014). Following acute demyelination, astrocytes respond to ET-1 via their endothelin receptor B by upregulating the Notch1 receptor ligand, jagged1 (Hammond et al., 2014, 2015). Astrocyte-induced Notch1 activation is known to inhibit OPC differentiation and remyelination. Interestingly, this astrocyte jagged1-Notch1 interaction resolves to allow OPC differentiation after a period of OPC expansion. Astrocytes could, therefore, be delaying OPC differentiation to allow sufficient proliferation of OPCs (Zhang et al., 2009; Hammond et al., 2014). This notch-mediated interaction may be relevant to MS considering a histological analysis of lesions shows that astrocytes express jagged 1 and OPCs express Notch1 (John et al., 2002). This is important as it is thought that a differentiation and maturation failure of OPCs is a significant contributor to 
remyelination failure in MS lesions (Kuhlmann et al., 2008; Duncan et al., 2017).

\section{Astrocytes as Regulators of the Extracellular Matrix (ECM)}

Astrocytes are also major modulators of the extracellular matrix (ECM). The ECM is composed of several molecules which can influence OPC function (Pu et al., 2018). Astrocytes are major producers of the ECM molecules high molecular weight hyaluronan (Back et al., 2005), Tenascin-C (Gutowski et al., 1999), fibronectin (Stoffels et al., 2013), and various members of the chondroitin sulfate proteoglycan family (Jones et al., 2003; Siebert et al., 2014). In addition to providing chemical signals, the mechanical stiffness of the ECM significantly influences the proliferation and differentiation of OPCs in vivo. It was recently shown that aging rodents have a stiffer ECM, resulting in decreased OPC proliferation and differentiation (Segel et al., 2019). When the mechanosensitive ion channel PIEZO1 is inhibited, OPCs are able to restore their loss of function in proliferation and differentiation. In addition to inhibiting OPC maturation and axon regeneration, these molecules exert immunomodulatory effects on several members of the immune system (Stephenson et al., 2018). For example, when chondroitin sulfate proteoglycans are added to murine macrophages in vitro, these cells significantly upregulate their production of pro-inflammatory cytokines, matrix metalloproteinases, as well as displaying an increase in migration (Stephenson et al., 2018). In this study, these ECM molecules were observed around perivascular cuffs in the EAE model. Pharmacologically inhibiting the synthesis of these molecules in this model resulted in reduced immune cell infiltration and decreased clinical severity (Stephenson et al., 2019). Although not yet addressed, the production of such inhibitory molecules may be influenced by the phenotypic state adopted by astrocytes.

\section{Astrocyte Role in Lipid Metabolism}

Astrocytes play a central role in lipid metabolism. As the BBB limits the entry of several lipoproteins from the peripheral circulation, the CNS has developed a tightly regulated system in which to regulate the production of lipid species such as arachidonic acid, docosahexanoic acid, and cholesterol (Moore, 2001; Dietschy, 2009). Astrocytes are the major producers of cholesterol and the cholesterol carrier, apolipoprotein E (APOE) under homeostatic conditions (Boyles et al., 1985). Cholesterol is a major constituent of cell membranes and myelin and is therefore critical in normal CNS functioning (Linton et al., 1991). Rodent neurons do not readily synthesize cholesterol and depend on astrocytes for their source of cholesterol (Nieweg et al., 2009). As astrocyte-derived cholesterol is important for normal neuronal functioning, it is likely that transport of cholesterol to oligodendrocytes from astrocytes or other glial cells such as microglia is important in myelin synthesis. Indeed, it was recently shown that demyelinated white matter lesions from aging mice have deficient reverse cholesterol transport that was associated with reduced remyelination (Cantuti-Castelvetri et al., 2018). Cantuti-Castelvetri et al. (2018) found that stimulating reverse cholesterol transport enhanced remyelination in the aging CNS, highlighting the role of lipid metabolism in myelin synthesis. Whether cholesterol exported by astrocytes and macrophages/microglia can be directly taken up by OPCs responding to a demyelinated lesion was not addressed in this study and is yet to be determined. This area is of direct importance as several small molecules capable of stimulating oligodendrogenesis act on the cholesterol biosynthesis pathways (Hubler et al., 2018). Importantly GFAP-expressing reactive astrocytes in EAE mice have decreased cholesterol synthesis, which may limit remyelination efficiency (Itoh et al., 2018), suggesting that autoimmunity may impair cholesterol synthesis.

Medications used to treat hypercholesterolemia (statins) seem to show some benefit in secondary progressive MS (Chataway et al., 2014). High-dose statin treatment resulted in a $43 \%$ reduction in brain atrophy compared to placebo. As statins have effects on the immune system, it is unclear whether the therapeutic efficacy of statins in secondary progressive MS are mediated through cholesterol modulation or other indirect mechanisms (Eshaghi et al., 2019). It is important to note that statins did not influence relapse risk, disease progression or disability scores in people with MS in combination with interferon therapy (Bhardwaj et al., 2012).

\section{Astrocytes Regulate CNS Schwann Cell Myelin and Secrete Growth Factors}

Astrocytes are thought to regulate the degree to which remyelination is favored by OPC-derived oligodendrocytes or SCs (Zawadzka et al., 2010; Monteiro de Castro et al., 2015). In the absence of astrocytes, more SC remyelination is observed. The mechanism by which astrocytes regulate the fate choice of OPCs is unclear but may be due to interactions in BMP/Wnt signaling within the lesion microenvironment (Ulanska-Poutanen et al., 2018). Although SCs remyelination appears to re-establish conduction capacity within CNS axons (Smith et al., 1979; Blight and Young, 1989), it is not yet clear whether SCs differ from oligodendrocytes in the provision of metabolic support to axons. Similarly, it is unclear how different myelin sheath thicknesses between oligodendrocytes and SCs affect the timing of axonal conduction.

Astrocyte secretion of neurotrophins, a class of proteins that induce the growth and survival of neuronal cells, are involved in remyelination. For example, astrocytes can regulate myelin protein synthesis by the release of brain-derived neurotrophic factor (BDNF; Fulmer et al., 2014). In the cuprizone model of demyelination, the activation of OPC-expressed BDNF receptor TrkB promotes remyelination as reflected by an increase in OPC differentiation, the number of remyelinated axons and myelin sheath thickness (Fletcher et al., 2018). Furthermore, astrocytes secrete the mitogen platelet-derived growth factor-A (PDGF-A) to act on OPCs, which can promote proliferation (Wolswijk and Noble, 1992; Redwine and Armstrong, 1998; Frost et al., 2003). Lesions from MS also display PDGFR $\alpha$ expression on proliferating cells (Maeda et al., 2001). Astrocytes are also thought to produce leukemia inhibitory factor, ciliary neurotrophic factor, and insulin-like growth factor-1, all of which have been implicated in supporting OPC maturation (Moore et al., 2011). 
Taken together, the role of astrocytes during remyelination is complex and incompletely understood (Figure 2). Release of growth factors and lipid metabolism is required for remyelination, yet astrocytes also produce several inhibitory ECM molecules that impair remyelination. The expression of notch ligands by astrocytes also serves as a break for remyelination. How astrocytes are regulated through the continuum of remyelination is yet to be defined, but may provide an explanation for their diverse roles during remyelination.

\section{NON-MYELINATING ROLES OF OLIGODENDROCYTE LINEAGE CELLS DURING REMYELINATION}

The non-myelinating roles of oligodendrocyte lineage cells are being increasingly realized and may provide new avenues for therapeutic intervention. During development and into adulthood, OPC differentiation is restricted to forming mature oligodendrocytes (Kang et al., 2010; Young et al., 2013; Huang et al., 2019) but during traumatic injury or demyelination OPCs act as multipotent progenitor cells (Richardson et al., 2011; Crawford et al., 2014) capable of differentiating into other neural lineage cells such as astrocytes and SCs (Zawadzka et al., 2010; Assinck et al., 2017b; Hackett et al., 2018; Huang et al., 2018). Beyond differentiating into other lineages, OPCs respond to disruptions in tissue homeostasis in a manner reminiscent of microglia. For example, OPCs proliferate and extend their processes to surround local injury sites (Hughes et al., 2013), albeit the kinetics of this process extension are slower than microglia (Davalos et al., 2005; Nimmerjahn et al., 2005). OPCs also migrate to areas of injury and proliferate to compensate for the loss of adjacent OPCs, again reminiscent of microglia. The high proliferative capacity and robust response to tissue injury suggest OPCs themselves may be major regulators of repair. Indeed a number of studies now indicate that the response of OPCs is critical for modulating inflammation, altering glial scarring and potentially regulating angiogenesis. The subsequent sections will review the evidence that OPCs are subverted to directly perform additional functions in CNS repair with an emphasis on how modulating these functions may offer new therapeutic strategies.

\section{Inflammatory Nature of Oligodendrocyte Progenitor Cells}

The rapid proliferation and migration to areas of tissue damage leave OPCs ideally situated to regulate subsequent immune responses. OPCs express many microglia-enriched genes but often at lower levels. For example, the homeostatic microglia marker CX3CR1 is expressed by OPCs (Voronova et al., 2017). Accordingly, OPCs express a number of critical modulators of the inflammatory response including IL-33 and the low-affinity Fc receptor (Fcgr2b) during EAE (Falcão et al., 2018), the latter of which is normally only expressed by microglia (Zhang et al., 2014). Transcriptomic analyses of OPCs reveal an increase in expression of the inflammasome-associated cytokines IL-1 $\beta$ and the chemokine CCL2 during demyelination (Moyon et al., 2015). It should be noted, however, that OPCs were isolated by Moyon et al. (2015) based on PDGFR $\alpha$ expression, which is also enriched in a population of pericytes (Assinck et al., 2017b), so these results should be interpreted with caution. However, recent single-cell RNA sequencing of OPCs during EAE (Falcão et al., 2018) and in MS (Jakubzick et al., 2017) confirms that these cells express a number of proinflammatory genes typically restricted to microglia/macrophages (Butovsky et al., 2014; Zhang et al., 2014). For example in response to IFN $\gamma$, OPCs go on to express the antigen presentation molecules MHC-I/II (Falcão et al., 2018). OPCs use MHCI/II to activate T-cells both in vivo and in vitro (Falcão et al., 2018; Kirby et al., 2018), and the capacity to cross-present antigens to CD8 T-cells was confirmed in vivo (Kirby et al., 2018). Taken together, inflammatory demyelination triggers OPCs to express pro-inflammatory cytokines and subsequently present antigens to T-cells.

Given that OPCs can perpetuate an inflammatory response raises the possibility that they might directly induce damage in autoimmune disease. Indeed, the induction of pro-inflammatory genes in OPCs during autoimmune demyelination may be necessary for subsequent demyelination. Blocking the activation of NF-кB by deleting Act1 in NG2+ glia blocks the development of EAE-induced demyelination and diminishes inflammatory gene expression following the adoptive transfer of MOG $_{35-55}$ Th-17 cells (Kang et al., 2013). Thus, the co-option of OPCs into a pro-inflammatory phenotype during Th-17-mediated autoimmune disease likely drives subsequent tissue damage. Additionally, the co-opting of OPCs to perpetuate an inflammatory response may leave them unable to adequately differentiate into new remyelinating oligodendrocytes, a possibility that remains to be proven. Indeed, the adoptive transfer of autoimmune T-cells (Baxi et al., 2015) or engraftment of lymphocytes from people with MS into mice with LPC-induced lesions (El Behi et al., 2017) slows remyelination, which is consistent with OPC immune activities impairing their differentiation. Likewise, following cuprizone demyelination, the transfer of effector T cells or IFN $\gamma$ impairs oligodendrocyte differentiation and is associated with the increased presentation of antigens by OPCs to CD8+ T cells (Kirby et al., 2018).

This co-option of OPCs into an inflammatory phenotype during autoimmune demyelination raises the intriguing possibility that the pro-inflammatory OPC phenotype likely drives tissue damage and may impair effective remyelination. Current FDA-approved therapeutics for MS target autoimmune damage in the CNS, and as such, they may have an unexpected benefit to diminish the co-option of OPCs, therefore, "freeing" them so that they can effectively remyelinate. In accordance, both the switch of microglia to a less inflammatory phenotype (Miron et al., 2013) and the transfer of regulatory T-cells promote remyelination following chemical demyelination (Dombrowski et al., 2017).

\section{Oligodendrocyte Lineage Cells During Glial Scarring}

When the extent of trauma or tissue injury necessitates glial scar formation, OPCs' role is to modify other cells that contribute to scar formation such as astrocytes or pericytes 


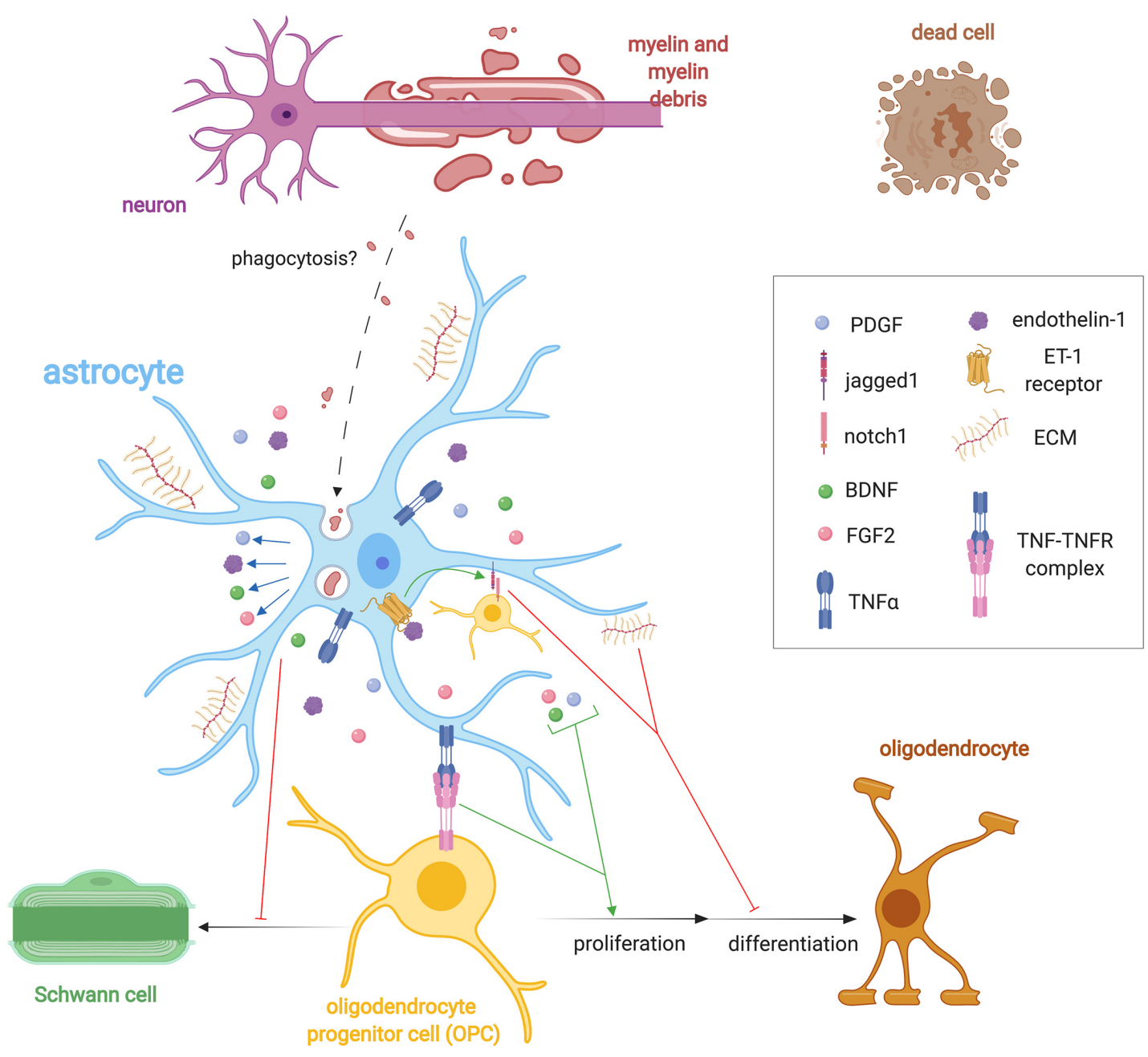

FIGURE 2 | Importance of astrocyte regulation of remyelination. Following demyelination, astrocytes help regulate OPC behavior via the expression of extracellular matrix (ECM) molecules such as CSPGs, hyluronan, fibronectin, and tenacin C, endothelin-1 and growth factor secretion such as FGF2, brain-derived neurotrophic factor (BDNF), and PDGF. Endothelin-1, through autocrine and paracrine signaling, stimulates the expression of the notch ligand jagged1 that antagonizes remyelination. Astrocytes control the fate choice of OPCs following demyelination by antagonizing their differentiation into Schwann cells (SCs). Astrocytes may phagocytose myelin debris, but this has only been validated in vitro. They also express TNF- $\alpha$, which binds to TNFR2 to promote remyelination.

(Hackett et al., 2016; Huang et al., 2018) and in some cases directly such as astrocytes (Rodriguez et al., 2014; Hesp et al., 2018). With a milder injury, OPCs have a much-reduced capacity to differentiate into astrocytes (Zawadzka et al., 2010). If proliferating $\mathrm{NG} 2+$ cells-which are composed of OPCs, pericytes, SCs and activated microglia/macrophage following traumatic SCI (McTigue et al., 2006)-are depleted, glial scar formation is dramatically impaired (Hesp et al., 2018). The result of NG2+ cell depletion is prolonged hemorrhage, larger lesions, and more pronounced edema (Hesp et al., 2018). Taken together, the proliferation and activation of NG2+ glia, which prominently includes OPCs, is necessary for proper formation of the glial scar that restricts ongoing secondary damage to tissue following traumatic injury. Given that scar formation is associated with ECM molecules inhibitory to remyelination, this raises the intriguing possibility that OPCs indirectly regulate ECM molecules known to inhibit remyelination.

\section{Oligodendrocyte Lineage Cells Interact With and Regulate the Vasculature}

During development, OPCs migrate along blood vessels in order to successfully distribute throughout the parenchyma, a step that is necessary for their subsequent differentiation into myelinating oligodendrocytes (Tsai et al., 2016). The secretion of stromal cell-derived factor 1 (SDF1) by endothelial cells attracts OPCs by binding to CXCR4, which is abundantly expressed on OPCs when Wnt-tone is high (Tsai et al., 2016). However, signaling between OPCs and endothelial cells is bidirectional, and given OPCs' location along blood vessels in development (Tsai et al., 2016), they are ideally positioned to sense oxygen 
levels and regulate angiogenesis. OPCs sense oxygen tension within the parenchyma via HIF $1 / 2 \alpha$ (Yuen et al., 2014), a protein sensor that is stabilized under hypoxic conditions (Wang et al., 1995; Majmundar et al., 2010). Experimentally stabilizing HIF in OPCs-and therefore mimicking hypoxia for these cells-promotes angiogenesis in both the cortex and corpus callosum likely through the secretion of soluble factors (Yuen et al., 2014). A mechanism emerges in which endothelial cells are necessary for the initial migration of OPCs throughout the parenchyma, which in turn, drive angiogenesis until oxygen tension is sufficient to support proper oligodendrocyte differentiation and myelination (Yuen et al., 2014; Tsai et al., 2016). Paracrine signaling between OPCs and endothelial cells is therefore critical for proper developmental myelination.

Interestingly, recent studies suggest the angiogenic activities of OPCs can be subverted under pathological conditions. In development, heightened OPC clustering along blood vessels disrupts $\mathrm{BBB}$ function resulting in lymphocyte trafficking in the CNS parenchyma. Like development (Tsai et al., 2016), OPCs migrate along blood vessels during remyelination (Niu et al., 2019). In active MS lesions, OPCs become trapped and cluster along blood vessels. It is unclear if this heightened clustering is due to local hypoxia within MS lesions or inflammation. Cytokines like IL-1 $\beta$ stimulates OPCs to secrete factors that promote angiogenesis in vitro, suggesting inflammation may also regulate OPC-dependent angiogenesis. Excessive Wnt signaling in OPCs not only induced clustering of OPCs but also increased the expression of Wif1, which suppresses tight junction formation in endothelial cells (Niu et al., 2019). Indeed hypoperfusion are present in both the NAWM and NAGM in MS potentially inducing a hypoxic environment (Law et al., 2004; Varga et al., 2009). Inflammation may also subvert OPCs to associate with blood vessels and block their ability to fully differentiate in MS. Given that excessive interactions between OPCs and blood vessels during development are sufficient to trigger pathological immunity, it will be interesting to examine if this interaction promotes pathology in models of inflammatory demyelination like EAE.

Taken together, OPCs are increasingly being recognized for their roles other than differentiating into oligodendrocytes during remyelination (Figure 3). OPCs morphologically respond to injury in a way comparable to microglia, they secrete cytokines, and they regulate scar formation. In these capacities OPCs are an alternative CNS-innate immune cell. OPCs are also responsive to oxygen levels and are important regulators of angiogenesis.

\section{REMYELINATION DECLINES WITH AGE}

Remyelination, as with any regenerative process, declines in efficiency with age (Shields et al., 1999; Sim et al., 2002; Ruckh et al., 2012). OPC proliferation and differentiation, which are necessary processes for remyelination, are reduced with age (Sim et al., 2002). In fact, dorsally-derived OPCs in the spinal cord are the predominant source of remyelination in young mice, but contribute less in aged animals (Crawford et al., 2016b). Age can intrinsically alter OPCs directly as old OPCs display a different global DNA methylation profile that alters and/or diminishes their response to pro-remyelinating factors (Zhou et al., 2019). Aging also decreases the recruitment of histone deacetylases (HDACs) in OPCs-epigenetic regulators of gene expression-that leads to a decrease in remyelination efficiency. In OPCs, HDACs downregulate the expression of many transcription factors that inhibit OPC differentiation, including Hes5 and Sox2. They, therefore, regulate remyelination by controlling OPC differentiation (Liu et al., 2006; Shen et al., 2008).

Age-impaired remyelination is also due to impaired innate immune cell function. The removal of inhibitory myelin debris by microglia/macrophages is impaired by aging (Natrajan et al., 2015; Safaiyan et al., 2016; Cantuti-Castelvetri et al., 2018; Rawji et al., 2018). In LPC-induced lesions, aging microglia/macrophages display a decrease in microenvironment surveillance activity and a decrease in phagocytic activity (Rawji et al., 2018). Furthermore, aging microglia/macrophage lysosomal degradation of myelin is diminished as reflected by the accumulation of myelin proteins in microglial lysosomes of aging mice (Safaiyan et al., 2016). This accumulation of myelin debris inside of microglia could be due to a deficiency in reverse cholesterol transport as remyelination efficiency increased when mice with LPC-induced focal demyelination were treated with $\mathrm{H} \beta \mathrm{CD}$, a drug that stimulates cholesterol efflux from cells (Cantuti-Castelvetri et al., 2018). These findings raise the possibility that targeting the phagocytic pathway of microglia/macrophages could improve the efficiency of the myelin debris clearance.

Why myelin debris clearance declines are likely multifaceted? Recently, a CRISPR-Cas9 knockout screen identified CD22 as a negative regulator of microglia phagocytosis that increases with age (Pluvinage et al., 2019). Many factors, such as RetinoidX-Receptor- $\alpha$ (RXR- $\alpha)$, fractalkine receptor CX3CR1 and Galectin-3 (Gal-3) can also influence the ability of microglia to phagocytose (Lampron et al., 2015; Natrajan et al., 2015; Reichert and Rotshenker, 2019). RXR- $\alpha$ is a ligand-activated transcription factor that controls a variety of genetic programs, including immune cell-related functions (Dawson and Xia, 2012). Natrajan et al. (2015) demonstrate that RXR- $\alpha$ knockout from young macrophages in mice LPC-induced lesion delays myelin debris clearance and remyelination, and also that stimulating RXR- $\alpha$ in monocytes from MS patients in vitro improves this normally inefficient myelin debris phagocytosis. There is now an ongoing clinical trial using an RXR- $\alpha$ agonist (EudraCT number: 2014-003145-99). Similarly, the chemokine receptor CX3CR1 - enriched in microglia-is critical for myelin debris clearance following cuprizone-induced demyelination (Lampron et al., 2015). Ruckh et al. (2012) found that in the LPC-induced demyelination model, the systemic circulatory system of young mice can restore the efficiency of OPC proliferation, differentiation, and remyelination in aged mice to levels near those observed in young mice. They were able to show these differences by joining the circulatory systems of young and old mice in pairs through heterochronic parabiosis. This rejuvenation of remyelination suggests that reversing the peripheral immune system can partially restore 


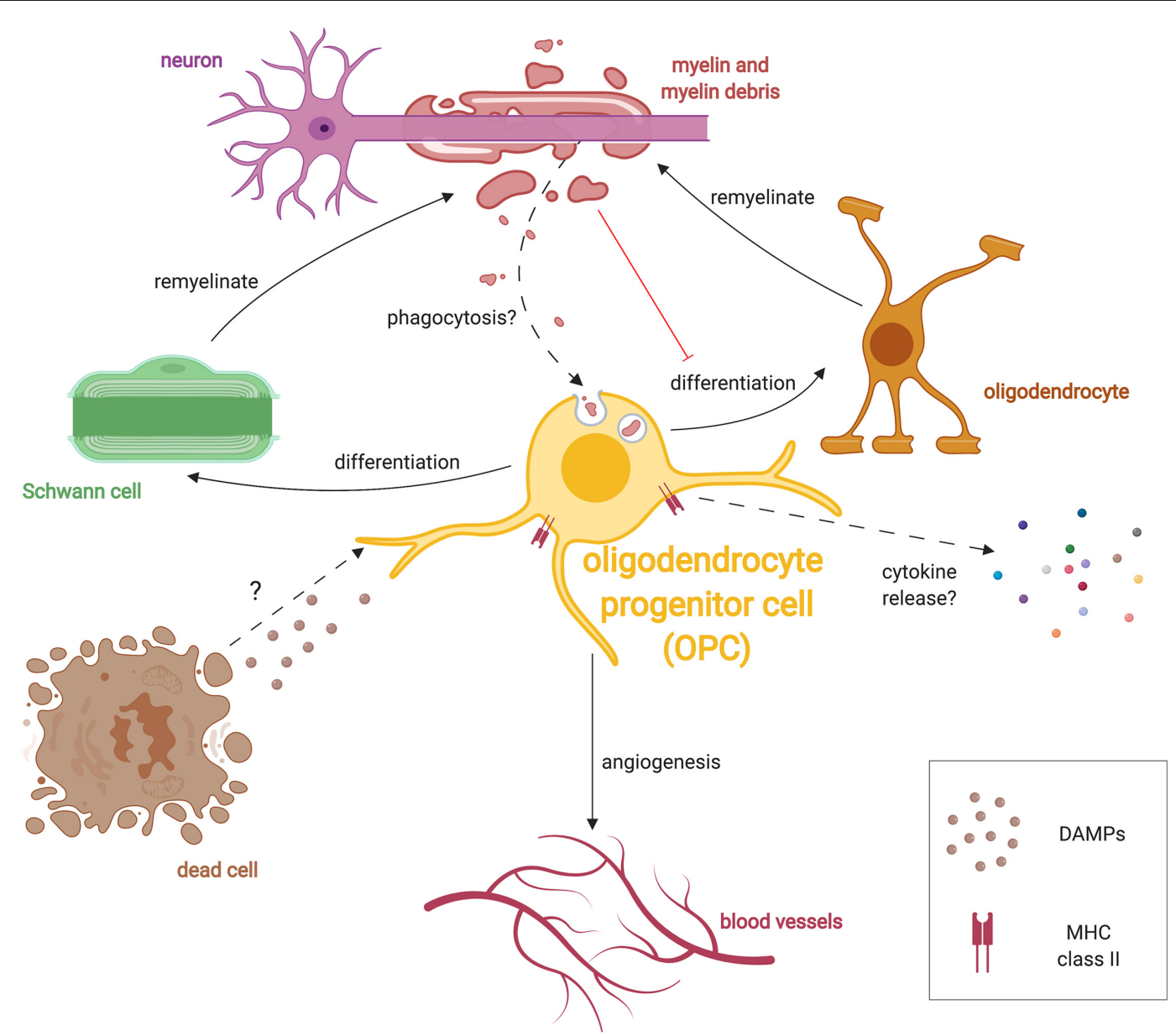

FIGURE 3 | Multiple roles of OPCs during remyelination. After damage, OPCs respond to injury by extending processes, migrating and proliferating following injury presumably in response to unknown DAMPs. OPCs can differentiate into either oligodendrocytes or SCs following demyelination. OPCs also respond to hypoxic conditions and promote angiogenesis. Similar to microglia, OPCs have been shown to phagocytose debris in culture, and may also do so in vivo. Given that myelin debris inhibits OPC lineage progression, phagocytosis of debris may subvert OPCs until debris clearance is completed. OPCs in the diseased state are also known to express the antigen-presenting protein, MHC-II, and presumably release specific cytokines which alter the immune response.

age-dependent decline in remyelination potential. In fact, several human trials such as the Stanford Parkinson's Disease Plasma Study (NCT02968433) infuse plasma from young people to diseased patients. However, a proper evaluation of the blood-borne rejuvenating factors is needed before any similar trial can be conducted for demyelinating diseases such as MS.

Peripheral changes during aging can also impart effects onto innate immune cells such as microglia. For example, peripheral blood from aged mice is sufficient to lower the levels of type II interferon in the choroid plexus, which is linked to cognitive decline, a common symptom observed in MS patients (Franklin et al., 1989; Baruch et al., 2014). Microglia also have interferon phenotypic changes during aging, in this case, driven in part by higher levels of IFN-I cytokines (Deczkowska et al., 2017) that likely come from peripheral sources. Furthermore, retro-orbital injection of plasma from aging mice to young mice is sufficient to activate microglia (Yousef et al., 2019). Peripheral immune changes are therefore important in regulating the innate immune system in the CNS.

\section{CONCLUSION}

Remyelination involves a complex interplay between the oligodendrocyte lineage cells that produce the myelin, the astrocytes and the other innate immune cells that regulate the microenvironment of remyelination. Microglia and CNS-infiltrating macrophages regulate the lesion environment and make it suitable for remyelination by activities such as the removal of inhibitory myelin debris. Astrocytes secrete growth factors and provide key lipids species, but also produce inhibitory ECM molecules and the Notch ligand Jagged. OPCs are the key source of remyelinating oligodendrocytes but are now recognized to also regulate angiogenesis, respond to injury and secrete cytokines suggesting they may also be a brain resident immune cell. Given that boosting remyelination 
spares venerable axons (Mei et al., 2016), more work is required to examine how these cells interact with one another during remyelination.

\section{AUTHOR CONTRIBUTIONS}

$\mathrm{CB}, \mathrm{KR}, \mathrm{GD}$ and JP drafted and reviewed this manuscript. $\mathrm{MH}$ and $\mathrm{CB}$ constructed the figures. JP supervised the drafting of this manuscript.

\section{REFERENCES}

Ajami, B., Bennett, J. L., Krieger, C., McNagny, K. M., and Rossi, F. M. (2011). Infiltrating monocytes trigger EAE progression, but do not contribute to the resident microglia pool. Nat. Neurosci. 14, 1142-1149. doi: 10.1038/ nn. 2887

Antony, J. M., Paquin, A., Nutt, S. L., Kaplan, D. R., and Miller, F. D. (2011). Endogenous microglia regulate development of embryonic cortical precursor cells. J. Neurosci. Res. 89, 286-298. doi: 10.1002/jnr.22533

Armstrong, R. C., Mierzwa, A. J., Sullivan, G. M., and Sanchez, M. A. (2016). Myelin and oligodendrocyte lineage cells in white matter pathology and plasticity after traumatic brain injury. Neuropharmacology 110, 654-659. doi: 10.1016/j.neuropharm.2015.04.029

Arnett, H. A., Mason, J., Marino, M., Suzuki, K., Matsushima, G. K., and Ting, J. P. (2001). TNF- $\alpha$ promotes proliferation of oligodendrocyte progenitors and remyelination. Nat. Neurosci. 4, 1116-1122. doi: 10.1038/nn738

Assinck, P., Duncan, G. J., Hilton, B. J., Plemel, J. R., and Tetzlaff, W. (2017a). Cell transplantation therapy for spinal cord injury. Nat. Neurosci. 20, 637-647. doi: 10.1038/nn.4541

Assinck, P., Duncan, G. J., Plemel, J. R., Lee, M. J., Stratton, J. A., Manesh, S. B., et al. (2017b). Myelinogenic plasticity of oligodendrocyte precursor cells following spinal cord contusion injury. J. Neurosci. 37, 8635-8654. doi: 10.1523/jneurosci.2409-16.2017

Back, S. A., Tuohy, T. M., Chen, H., Wallingford, N., Craig, A., Struve, J., et al. (2005). Hyaluronan accumulates in demyelinated lesions and inhibits oligodendrocyte progenitor maturation. Nat. Med. 11, 966-972. doi: $10.1038 / \mathrm{nm} 1279$

Baker, D., Butler, D., Scallon, B. J., O’Neill, J. K., Turk, J. L., and Feldmann, M. (1994). Control of established experimental allergic encephalomyelitis by inhibition of tumor necrosis factor (TNF) activity within the central nervous system using monoclonal antibodies and TNF receptor-immunoglobulin fusion proteins. Eur. J. Immunol. 24, 2040-2048. doi: 10.1002/eji.1830240916

Bartzokis, G., Lu, P. H., Heydari, P., Couvrette, A., Lee, G. J., Kalashyan, G., et al. (2012). Multimodal magnetic resonance imaging assessment of white matter aging trajectories over the lifespan of healthy individuals. Biol. Psychiatry 72, 1026-1034. doi: 10.1016/j.biopsych.2012.07.010

Baruch, K., Deczkowska, A., David, E., Castellano, J. M., Miller, O., Kertser, A., et al. (2014). Aging-induced type I interferon response at the choroid plexus negatively affects brain function. Science 346, 89-93. doi: 10.1126/science. 1252945

Baxi, E. G., DeBruin, J., Tosi, D. M., Grishkan, I. V., Smith, M. D., Kirby, L. A., et al. (2015). Transfer of myelin-reactive th17 cells impairs endogenous remyelination in the central nervous system of cuprizone-fed mice. J. Neurosci. 35, 8626-8639. doi: 10.1523/jneurosci.3817-14.2015

Bejanin, A., Desgranges, B., Joie La, R., Landeau, B., Perrotin, A., Mezenge, F., et al. (2017). Distinct white matter injury associated with medial temporal lobe atrophy in Alzheimer's versus semantic dementia. Hum. Brain Mapp. 38, 1791-1800. doi: 10.1002/hbm.23482

Bernier, L. P., Bohlen, C. J., York, E. M., Choi, H. B., Kamyabi, A., DissingOlesen, L., et al. (2019). Nanoscale surveillance of the brain by microglia via cAMP-regulated filopodia. Cell Rep. 27, 2895.e4-2908.e4. doi: 10.1016/j.celrep. 2019.05.010

Bhardwaj, S., Coleman, C. I., and Sobieraj, D. M. (2012). Efficacy of statins in combination with interferon therapy in multiple sclerosis: a meta-analysis. Am. J. Health Syst. Pharm. 69, 1494-1499. doi: 10.2146/ajhp110675

\section{FUNDING}

KR is supported by the MS Society of Canada. GD is supported by a National Multiple Sclerosis Society fellowship. This work was funded by the University of Alberta, the University Hospital Foundation Medical Research Competition, the Azrieli Foundation and Brain Canada, through the Canada Brain Research fund, with support of Health Canada and the Funding Partner(s).

Black, J. A., Newcombe, J., Trapp, B. D., and Waxman, S. G. (2007). Sodium channel expression within chronic multiple sclerosis plaques. J. Neuropathol. Exp. Neurol. 66, 828-837. doi: 10.1097/nen.0b013e3181462841

Blakemore, W. F. (1974). Pattern of remyelination in the CNS. Nature 249, 577-578. doi: 10.1038/249577a0

Blight, A. R., and Young, W. (1989). Central axons in injured cat spinal cord recover electrophysiological function following remyelination by Schwann cells. J. Neurol. Sci. 91, 15-34. doi: 10.1016/0022-510x(89)90073-7

Bodini, B., Veronese, M., García-Lorenzo, D., Battaglini, M., Poirion, E., Chardain, A., et al. (2016). Dynamic imaging of individual remyelination profiles in multiple sclerosis. Ann. Neurol. 79, 726-738. doi: 10.1002/ana. 24620

Bostock, H., Sears, T. A., and Sherratt, R. M. (1981). The effects of 4-aminopyridine and tetraethylammonium ions on normal and demyelinated mammalian nerve fibres. J. Physiol. 313, 301-315. doi: 10.1113/jphysiol.1981.sp013666

Bostock, H., Sherratt, R. M., and Sears, T. A. (1978). Overcoming conduction failure in demyelinated nerve fibres by prolonging action potentials. Nature 274, 385-387. doi: 10.1038/274385a0

Boutajangout, A., and Wisniewski, T. (2013). The innate immune system in Alzheimer's disease. Int. J. Cell Biol. 2013:576383. doi: 10.1155/2013/ 576383

Boyles, J. K., Pitas, R. E., Wilson, E., Mahley, R. W., and Taylor, J. M. (1985). Apolipoprotein E associated with astrocytic glia of the central nervous system and with nonmyelinating glia of the peripheral nervous system. J. Clin. Invest. 76, 1501-1513. doi: 10.1172/jci112130

Bramow, S., Frischer, J. M., Lassmann, H., Koch-Henriksen, N., Lucchinetti, C. F., Sørensen, P. S., et al. (2010). Demyelination versus remyelination in progressive multiple sclerosis. Brain 133, 2983-2998. doi: 10.1093/brain/awq250

Brown, R. A., Narayanan, S., Banwell, B., Arnold, D. L., and Canadian Pediatric Demyelinating Disease Network. (2014). Magnetization transfer ratio recovery in new lesions decreases during adolescence in pediatric-onset multiple sclerosis patients. Neuroimage Clin. 6, 237-242. doi: 10.1016/j.nicl.2014.09.003

Bujalka, H., Koenning, M., Jackson, S., Perreau, V. M., Pope, B., Hay, C. M., et al. (2013). MYRF is a membrane-associated transcription factor that autoproteolytically cleaves to directly activate myelin genes. PLoS Biol. 11:e1001625. doi: 10.1371/journal.pbio.1001625

Butovsky, O., Jedrychowski, M. P., Moore, C. S., Cialic, R., Lanser, A. J., Gabriely, G., et al. (2014). Identification of a unique TGF- $\beta$-dependent molecular and functional signature in microglia. Nat. Neurosci. 17, 131-143. doi: $10.1038 / \mathrm{nn} .3599$

Cantuti-Castelvetri, L., Fitzner, D., Bosch-Queralt, M., Weil, M. T., Su, M., Sen, P., et al. (2018). Defective cholesterol clearance limits remyelination in the aged central nervous system. Science 359, 684-688. doi: 10.1126/science.aan4183

Caravagna, C., Jaouën, A., Desplat-Jégo, S., Fenrich, K. K., Bergot, E., Luche, H., et al. (2018). Diversity of innate immune cell subsets across spatial and temporal scales in an EAE mouse model. Sci. Rep. 8:5146. doi: 10.1038/s41598-01822872-y

Carmeli, C., Donati, A., Antille, V., Viceic, D., Ghika, J., Gunten von, A., et al. (2013). Demyelination in mild cognitive impairment suggests progression path to Alzheimer's disease. PLoS One 8:e72759. doi: 10.1371/journal.pone.0072759

Chataway, J., Schuerer, N., Alsanousi, A., Chan, D., MacManus, D., Hunter, K., et al. (2014). Effect of high-dose simvastatin on brain atrophy and disability in secondary progressive multiple sclerosis (MS-STAT): a randomised, placebo-controlled, phase 2 trial. Lancet 383, 2213-2221. doi: 10.1016/S01406736(13)62242-4 
Courties, G., Moskowitz, M. A., and Nahrendorf, M. (2014). The innate immune system after ischemic injury: lessons to be learned from the heart and brain. JAMA Neurol. 71, 233-236. doi: 10.1001/jamaneurol.2013.5026

Crawford, A. H., Stockley, J. H., Tripathi, R. B., Richardson, W. D., and Franklin, R. J. (2014). Oligodendrocyte progenitors: adult stem cells of the central nervous system? Exp. Neurol. 260, 50-55. doi: 10.1016/j.expneurol.2014. 04.027

Crawford, A. H., Tripathi, R. B., Foerster, S., McKenzie, I., Kougioumtzidou, E., Grist, M., et al. (2016a). Pre-existing mature oligodendrocytes do not contribute to remyelination following toxin-induced spinal cord demyelination. Am. J. Pathol. 186, 511-516. doi: 10.1016/j.ajpath.2015. 11.005

Crawford, A. H., Tripathi, R. B., Richardson, W. D., and Franklin, R. J. M. (2016b). Developmental origin of oligodendrocyte lineage cells determines response to demyelination and susceptibility to age-associated functional decline. Cell Rep. 15, 761-773. doi: 10.1016/j.celrep.2016.03.069

Crowe, M. J., Bresnahan, J. C., Shuman, S. L., Masters, J. N., and Beattie, M. S. (1997). Apoptosis and delayed degeneration after spinal cord injury in rats and monkeys. Nat. Med. 3, 73-76. doi: 10.1038/nm0197-73

Dai, X., Lercher, L. D., Clinton, P. M., Du, Y., Livingston, D. L., Vieira, C., et al. (2003). The trophic role of oligodendrocytes in the basal forebrain. J. Neurosci. 23, 5846-5853. doi: 10.1523/jneurosci.23-13-05846.2003

Davalos, D., Grutzendler, J., Yang, G., Kim, J. V., Zuo, Y., Jung, S., et al. (2005). ATP mediates rapid microglial response to local brain injury in vivo. Nat. Neurosci. 8, 752-758. doi: 10.1038/nn1472

Davies, C. L., and Miron, V. E. (2018). Distinct origins, gene expression and function of microglia and monocyte-derived macrophages in CNS myelin injury and regeneration. Clin. Immunol. 189, 57-62. doi: 10.1016/j.clim.2016. 06.016

Dawson, M. I., and Xia, Z. (2012). The retinoid X receptors and their ligands. Biochim. Biophys. Acta 1821, 21-56. doi: 10.1016/j.bbalip.2011.09.014

Deczkowska, A., Keren-Shaul, H., Weiner, A., Colonna, M., Schwartz, M., and Amit, I. (2018). Disease-associated microglia: a universal immune sensor of neurodegeneration. Cell 173, 1073-1081. doi: 10.1016/j.cell.2018.05.003

Deczkowska, A., Matcovitch-Natan, O., Tsitsou-Kampeli, A., Ben-Hamo, S., Dvir-Szternfeld, R., Spinrad, A., et al. (2017). Mef2C restrains microglial inflammatory response and is lost in brain ageing in an IFN-I-dependent manner. Nat. Commun. 8:717. doi: 10.1038/s41467-017-00769-0

Dehghan, S., Javan, M., Pourabdolhossein, F., Mirnajafi-Zadeh, J., and Baharvand, H. (2012). Basic fibroblast growth factor potentiates myelin repair following induction of experimental demyelination in adult mouse optic chiasm and nerves. J. Mol. Neurosci. 48, 77-85. doi: 10.1007/s12031-012-9777-6

Dietschy, J. M. (2009). Central nervous system: cholesterol turnover, brain development and neurodegeneration. Biol. Chem. 390, 287-293. doi: 10.1515/bc.2009.035

Dillenburg, A., Ireland, G., Holloway, R. K., Davies, C. L., Evans, F. L., Swire, M., et al. (2018). Activin receptors regulate the oligodendrocyte lineage in health and disease. Acta Neuropathol. 135, 887-906. doi: 10.1007/s00401-018-1813-3

Dimitriadou, V., Pang, X., and Theoharides, T. C. (2000). Hydroxyzine inhibits experimental allergic encephalomyelitis (EAE) and associated brain mast cell activation. Int. J. Immunopharmacol. 22, 673-684. doi: 10.1016/s01920561(00)00029-1

Dimou, L., Simon, C., Kirchhoff, F., Takebayashi, H., and Gotz, M. (2008). Progeny of Olig2-expressing progenitors in the gray and white matter of the adult mouse cerebral cortex. J. Neurosci. 28, 10434-10442. doi: 10.1523/jneurosci.2831 $-08.2008$

Diserbo, M., Agin, A., Lamproglou, I., Mauris, J., Staali, F., Multon, E., et al. (2002). Blood-brain barrier permeability after $\gamma$ whole-body irradiation: an in vivo microdialysis study. Can. J. Physiol. Pharmacol. 80, 670-678. doi: 10.1139/ y02-070

Dombrowski, Y., O’Hagan, T., Dittmer, M., Penalva, R., Mayoral, S. R., Bankhead, P., et al. (2017). Regulatory T cells promote myelin regeneration in the central nervous system. Nat. Neurosci. 20, 674-680. doi: 10.1038/ nn. 4528

Döring, A., Sloka, S., Lau, L., Mishra, M., Minnen van, J., Zhang, X., et al. (2015). Stimulation of monocytes, macrophages and microglia by amphotericin B and macrophage colony-stimulating factor promotes remyelination. J. Neurosci. 35, 1136-1148. doi: 10.1523/jneurosci.1797-14.2015
Duncan, G. J., Manesh, S. B., Hilton, B. J., Assinck, P., Liu, J., Moulson, A., et al. (2018). Locomotor recovery following contusive spinal cord injury does not require oligodendrocyte remyelination. Nat. Commun. 9:3066. doi: 10.1038/s41467-018-05473-1

Duncan, I. D., Brower, A., Kondo, Y., Curlee, J. F., and Schultz, R. D. (2009). Extensive remyelination of the CNS leads to functional recovery. Proc. Natl. Acad. Sci. U S A 106, 6832-6836. doi: 10.1073/pnas.0812500106

Duncan, I. D., Marik, R. L., Broman, A. T., and Heidari, M. (2017). Thin myelin sheaths as the hallmark of remyelination persist over time and preserve axon function. Proc. Natl. Acad. Sci. U S A 114, E9685-E9691. doi: 10.1073/pnas. 1714183114

Duncan, G. J., Plemel, J. R., Assinck, P., Manesh, S. B., Muir, F. G. W., Hirata, R., et al. (2017). Myelin regulatory factor drives remyelination in multiple sclerosis. Acta Neuropathol. 134, 403-422. doi: 10.1007/s00401-017-1741-7

Duncan, I. D., Radcliff, A. B., Heidari, M., Kidd, G., August, B. K., and Wierenga, L. A. (2018). The adult oligodendrocyte can participate in remyelination. Proc. Natl. Acad. Sci. U S A 115, E11807-E11816. doi: 10.1073/pnas.1808064115

El Behi, M., Sanson, C., Bachelin, C., Guillot-Noel, L., Fransson, J., Stankoff, B., et al. (2017). Adaptive human immunity drives remyelination in a mouse model of demyelination. Brain 140, 967-980. doi: 10.1093/brain/awx008

Elmore, M. R., Najafi, A. R., Koike, M. A., Dagher, N. N., Spangenberg, E. E., Rice, R. A., et al. (2014). Colony-stimulating factor 1 receptor signaling is necessary for microglia viability, unmasking a microglia progenitor cell in the adult brain. Neuron 82, 380-397. doi: 10.1016/j.neuron.2014.02.040

Emery, B., Agalliu, D., Cahoy, J. D., Watkins, T. A., Dugas, J. C., Mulinyawe, S. B., et al. (2009). Myelin gene regulatory factor is a critical transcriptional regulator required for CNS myelination. Cell 138, 172-185. doi: 10.1016/j.cell.2009. 04.031

England, J. D., Gamboni, F., and Levinson, S. R. (1991). Increased numbers of sodium channels form along demyelinated axons. Brain Res. 548, 334-337. doi: 10.1016/0006-8993(91)91144-p

Eshaghi, A., Kievit, R. A., Prados, F., Sudre, C. H., Nicholas, J., Cardoso, M. J., et al. (2019). Applying causal models to explore the mechanism of action of simvastatin in progressive multiple sclerosis. Proc. Natl. Acad. Sci. U S A 116, 11020-11027. doi: 10.1073/pnas.1818978116

Falcão, A. M., Bruggen van, D., Marques, S., Meijer, M., Jakel, S., Agirre, E., et al. (2018). Disease-specific oligodendrocyte lineage cells arise in multiple sclerosis. Nat. Med. 24, 1837-1844. doi: 10.1038/s41591-018-0236-y

Fancy, S. P., Zhao, C., and Franklin, R. J. (2004). Increased expression of $\mathrm{Nkx} 2.2$ and Olig2 identifies reactive oligodendrocyte progenitor cells responding to demyelination in the adult CNS. Mol. Cell. Neurosci. 27, 247-254. doi: 10.1016/j.mcn.2004.06.015

Felts, P. A., Baker, T. A., and Smith, K. J. (1997). Conduction in segmentally demyelinated mammalian central axons. J. Neurosci. 17, 7267-7277. doi: 10.1523/jneurosci.17-19-07267.1997

Fife, B. T., Huffnagle, G. B., Kuziel, W. A., and Karpus, W. J. (2000). CC chemokine receptor 2 is critical for induction of experimental autoimmune encephalomyelitis. J. Exp. Med. 192, 899-905. doi: 10.1084/jem.192.6.899

Fletcher, J. L., Wood, R. J., Nguyen, J., Norman, E. M. L., Jun, C. M. K., Prawdiuk, A. R., et al. (2018). Targeting TrkB with a brain-derived neurotrophic factor mimetic promotes myelin repair in the brain. J. Neurosci. 38, 7088-7099. doi: 10.1523/jneurosci.0487-18.2018

Foster, R. E., Whalen, C. C., and Waxman, S. G. (1980). Reorganization of the axon membrane in demyelinated peripheral nerve fibers: morphological evidence. Science 210, 661-663. doi: 10.1126/science.6159685

Franklin, R. J. M., and Ffrench-Constant, C. (2017). Regenerating CNS myelinfrom mechanisms to experimental medicines. Nat. Rev. Neurosci. 18, 753-769. doi: 10.1038/nrn.2017.136

Franklin, R. J., and Ffrench-Constant, C. (2008). Remyelination in the CNS: from biology to therapy. Nat. Rev. Neurosci. 9, 839-855. doi: 10.1038/nrn2480

Franklin, G. M., Nelson, L. M., Filley, C. M., and Heaton, R. K. (1989). Cognitive loss in multiple sclerosis. Case reports and review of the literature. Arch. Neurol. 46, 162-167. doi: 10.1001/archneur.1989.00520380066014

Frischer, J. M., Weigand, S. D., Guo, Y., Kale, N., Parisi, J. E., Pirko, I., et al. (2015). Clinical and pathological insights into the dynamic nature of the white matter multiple sclerosis plaque. Ann. Neurol. 78, 710-721. doi: 10.1002/ana. 24497 
Frost, E. E., Nielsen, J. A., Le, T. Q., and Armstrong, R. C. (2003). PDGF and FGF2 regulate oligodendrocyte progenitor responses to demyelination. J. Neurobiol. 54, 457-472. doi: 10.1002/neu.10158

Frühbeis, C., Fröhlich, D., Kuo, W. P., Amphornrat, J., Thilemann, S., Saab, A. S., et al. (2013). Neurotransmitter-triggered transfer of exosomes mediates oligodendrocyte-neuron communication. PLoS Biol. 11:e1001604. doi: 10.1371/journal.pbio.1001604

Fulmer, C. G., VonDran, M. W., Stillman, A. A., Huang, Y., Hempstead, B. L., and Dreyfus, C. F. (2014). Astrocyte-derived BDNF supports myelin protein synthesis after cuprizone-induced demyelination. J. Neurosci. 34, 8186-8196. doi: 10.1523/jneurosci.4267-13.2014

Fünfschilling, U., Supplie, L. M., Mahad, D., Boretius, S., Saab, A. S., Edgar, J., et al. (2012). Glycolytic oligodendrocytes maintain myelin and long-term axonal integrity. Nature 485, 517-521. doi: 10.1038/nature11007

Giera, S., Luo, R., Ying, Y., Ackerman, S. D., Jeong, S. J., Stoveken, H. M., et al. (2018). Microglial transglutaminase-2 drives myelination and myelin repair via GPR56/ADGRG1 in oligodendrocyte precursor cells. Elife 7:e33385. doi: 10.7554/elife.33385

Ginhoux, F., Greter, M., Leboeuf, M., Nandi, S., See, P., Gokhan, S., et al. (2010). Fate mapping analysis reveals that adult microglia derive from primitive macrophages. Science 330, 841-845. doi: 10.1126/science.1194637

Gladue, R. P., Carroll, L. A., Milici, A. J., Scampoli, D. N., Stukenbrok, H. A., Pettipher, E. R., et al. (1996). Inhibition of leukotriene B4-receptor interaction suppresses eosinophil infiltration and disease pathology in a murine model of experimental allergic encephalomyelitis. J. Exp. Med. 183, 1893-1898. doi: 10.1084/jem.183.4.1893

Goldmann, T., Wieghofer, P., Jordao, M. J., Prutek, F., Hagemeyer, N., Frenzel, K., et al. (2016). Origin, fate and dynamics of macrophages at central nervous system interfaces. Nat. Immunol. 17, 797-805. doi: 10.1038/ni.3423

Goldmann, T., Wieghofer, P., Muller, P. F., Wolf, Y., Varol, D., Yona, S., et al. (2013). A new type of microglia gene targeting shows TAK1 to be pivotal in CNS autoimmune inflammation. Nat. Neurosci. 16, 1618-1626. doi: $10.1038 / \mathrm{nn} .3531$

Goldschmidt, T., Antel, J., Konig, F. B., Bruck, W., and Kuhlmann, T. (2009). Remyelination capacity of the MS brain decreases with disease chronicity. Neurology 72, 1914-1921. doi: 10.1212/WNL.0b013e3181a8260a

Gutowski, N. J., Newcombe, J., and Cuzner, M. L. (1999). Tenascin-R and C in multiple sclerosis lesions: relevance to extracellular matrix remodelling. Neuropathol. Appl. Neurobiol. 25, 207-214. doi: 10.1046/j.1365-2990.1999. 00176.x

Hackett, A. R., Lee, D. H., Dawood, A., Rodriguez, M., Funk, L., Tsoulfas, P., et al. (2016). STAT3 and SOCS3 regulate NG2 cell proliferation and differentiation after contusive spinal cord injury. Neurobiol. Dis. 89, 10-22. doi: 10.1016/j.nbd. 2016.01.017

Hackett, A. R., Yahn, S. L., Lyapichev, K., Dajnoki, A., Lee, D. H., Rodriguez, M., et al. (2018). Injury type-dependent differentiation of NG2 glia into heterogeneous astrocytes. Exp. Neurol. 308, 72-79. doi: 10.1016/j.expneurol. 2018.07.001

Haider, L., Fischer, M. T., Frischer, J. M., Bauer, J., Hoftberger, R., Botond, G., et al. (2011). Oxidative damage in multiple sclerosis lesions. Brain 134, 1914-1924. doi: 10.1093/brain/awr128

Hamada, M. S., and Kole, M. H. (2015). Myelin loss and axonal ion channel adaptations associated with gray matter neuronal hyperexcitability. J. Neurosci. 35, 7272-7286. doi: 10.1523/jneurosci.4747-14.2015

Hammond, T. R., Dufort, C., Dissing-Olesen, L., Giera, S., Young, A., Wysoker, A., et al. (2019). Single-cell RNA sequencing of microglia throughout the mouse lifespan and in the injured brain reveals complex cell-state changes. Immunity 50, 253.e6-271.e6. doi: 10.1016/j.immuni.2018.11.004

Hammond, T. R., Gadea, A., Dupree, J., Kerninon, C., Nait-Oumesmar, B., Aguirre, A., et al. (2014). Astrocyte-derived endothelin-1 inhibits remyelination through notch activation. Neuron 81, 588-602. doi: 10.1016/j. neuron.2013.11.015

Hammond, T. R., McEllin, B., Morton, P. D., Raymond, M., Dupree, J., and Gallo, V. (2015). Endothelin-B receptor activation in astrocytes regulates the rate of oligodendrocyte regeneration during remyelination. Cell Rep. 13, 2090-2097. doi: 10.1016/j.celrep.2015.11.002

Han, X., Li, Q., Lan, X., El-Mufti, L., Ren, H., and Wang, J. (2019). Microglial depletion with clodronate liposomes increases proinflammatory cytokine levels, induces astrocyte activation and damages blood vessel integrity. Mol. Neurobiol. 56, 6184-6196. doi: 10.1007/s12035-019-1502-9

Harris, J. J., and Attwell, D. (2012). The energetics of CNS white matter. J. Neurosci. 32, 356-371. doi: 10.1523/jneurosci.3430-11.2012

Haynes, S. E., Hollopeter, G., Yang, G., Kurpius, D., Dailey, M. E., Gan, W. B., et al. (2006). The P2Y12 receptor regulates microglial activation by extracellular nucleotides. Nat. Neurosci. 9, 1512-1519. doi: 10.1038/nn1805

Heppner, F. L., Greter, M., Marino, D., Falsig, J., Raivich, G., Hovelmeyer, N., et al. (2005). Experimental autoimmune encephalomyelitis repressed by microglial paralysis. Nat. Med. 11, 146-152. doi: 10.1038/nm1177

Hesp, Z. C., Yoseph, R. Y., Suzuki, R., Jukkola, P., Wilson, C., Nishiyama, A., et al. (2018). Proliferating NG2-cell-dependent angiogenesis and scar formation alter axon growth and functional recovery after spinal cord injury in mice. J. Neurosci. 38, 1366-1382. doi: 10.1523/jneurosci.3953-16.2017

Hickman, S. E., Kingery, N. D., Ohsumi, T. K., Borowsky, M. L., Wang, L. C., Means, T. K., et al. (2013). The microglial sensome revealed by direct RNA sequencing. Nat. Neurosci. 16, 1896-1905. doi: 10.1038/nn.3554

Hill, R. A., Li, A. M., and Grutzendler, J. (2018). Lifelong cortical myelin plasticity and age-related degeneration in the live mammalian brain. Nat. Neurosci. 21 , 683-695. doi: 10.1038/s41593-018-0120-6

Hinks, G. L., and Franklin, R. J. (1999). Distinctive patterns of PDGFA, FGF-2, IGF-I, and TGF- $\beta 1$ gene expression during remyelination of experimentally-induced spinal cord demyelination. Mol. Cell. Neurosci. 14, 153-168. doi: 10.1006/mcne.1999.0771

Hiremath, M. M., Saito, Y., Knapp, G. W., Ting, J. P., Suzuki, K., and Matsushima, G. K. (1998). Microglial/macrophage accumulation during cuprizone-induced demyelination in C57BL/6 mice. J. Neuroimmunol. 92, 38-49. doi: 10.1016/s0165-5728(98)00168-4

Hostenbach, S., D'haeseleer, M., Kooijman, R., and De Keyser, J. (2016). The pathophysiological role of astrocytic endothelin-1. Prog. Neurobiol. 144, 88-102. doi: 10.1016/j.pneurobio.2016.04.009

Huang, W., Bai, X., Stopper, L., Catalin, B., Cartarozzi, L. P., Scheller, A., et al. (2018). During development NG2 glial cells of the spinal cord are restricted to the oligodendrocyte lineage, but generate astrocytes upon acute injury. Neuroscience 385, 154-165. doi: 10.1016/j.neuroscience.2018.06.015

Huang, W., Guo, Q., Bai, X., Scheller, A., and Kirchhoff, F. (2019). Early embryonic NG2 glia are exclusively gliogenic and do not generate neurons in the brain. Glia 67, 1094-1103. doi: 10.1002/glia.23590

Hubler, Z., Allimuthu, D., Bederman, I., Elitt, M. S., Madhavan, M., Allan, K. C., et al. (2018). Accumulation of 8,9-unsaturated sterols drives oligodendrocyte formation and remyelination. Nature 560, 372-376. doi: 10.1038/s41586-0180360-3

Hughes, E. G., Kang, S. H., Fukaya, M., and Bergles, D. E. (2013). Oligodendrocyte progenitors balance growth with self-repulsion to achieve homeostasis in the adult brain. Nat. Neurosci. 16, 668-676. doi: 10.1038/nn.3390

Hwang, S. Y., Jung, J. S., Kim, T. H., Lim, S. J., Oh, E. S., Kim, J. Y., et al. (2006). Ionizing radiation induces astrocyte gliosis through microglia activation. Neurobiol. Dis. 21, 457-467. doi: 10.1016/j.nbd.2005.08.006

Irvine, K. A., and Blakemore, W. F. (2008). Remyelination protects axons from demyelination-associated axon degeneration. Brain 131, 1464-1477. doi: 10.1093/brain/awn080

Itoh, N., Itoh, Y., Tassoni, A., Ren, E., Kaito, M., Ohno, A., et al. (2018). Cell-specific and region-specific transcriptomics in the multiple sclerosis model: focus on astrocytes. Proc. Natl. Acad. Sci. U S A 115, E302-E309. doi: $10.1073 /$ pnas. 1716032115

Itoyama, Y., Webster, H. D., Richardson, E. P., and Trapp, B. D. (1983). Schwann cell remyelination of demyelinated axons in spinal cord multiple sclerosis lesions. Ann. Neurol. 14, 339-346. doi: 10.1002/ana.410140313

Jäkel, S., Agirre, E., Mendanha Falcão, A., Bruggen van, D., Lee, K. W., Knuesel, I., et al. (2019). Altered human oligodendrocyte heterogeneity in multiple sclerosis. Nature 566, 543-547. doi: 10.1038/s41586-019-0903-2

Jakubzick, C. V., Randolph, G. J., and Henson, P. M. (2017). Monocyte differentiation and antigen-presenting functions. Nat. Rev. Immunol. 17, 349-362. doi: 10.1038/nri.2017.28

John, G. R., Shankar, S. L., Shafit-Zagardo, B., Massimi, A., Lee, S. C., Raine, C. S., et al. (2002). Multiple sclerosis: re-expression of a developmental pathway that restricts oligodendrocyte maturation. Nat. Med. 8, 1115-1121. doi: $10.1038 / \mathrm{nm} 781$ 
Jones, L. L., Margolis, R. U., and Tuszynski, M. H. (2003). The chondroitin sulfate proteoglycans neurocan, brevican, phosphacan and versican are differentially regulated following spinal cord injury. Exp. Neurol. 182, 399-411. doi: 10.1016/s0014-4886(03)00087-6

Kang, S. H., Fukaya, M., Yang, J. K., Rothstein, J. D., and Bergles, D. E. (2010). NG2 ${ }^{+}$CNS glial progenitors remain committed to the oligodendrocyte lineage in postnatal life and following neurodegeneration. Neuron 68, 668-681. doi: 10.1016/j.neuron.2010.09.009

Kang, Z., Wang, C., Zepp, J., Wu, L., Sun, K., Zhao, J., et al. (2013). Act1 mediates IL-17-induced EAE pathogenesis selectively in $\mathrm{NG}^{+}$glial cells. Nat. Neurosci. 16, 1401-1408. doi: 10.1038/nn.3505

Kawabori, M., and Yenari, M. A. (2015). The role of the microglia in acute CNS injury. Metab. Brain Dis. 30, 381-392. doi: 10.1007/s11011-014-9531-6

Keren-Shaul, H., Spinrad, A., Weiner, A., Matcovitch-Natan, O., DvirSzternfeld, R., Ulland, T. K., et al. (2017). A unique microglia type associated with restricting development of Alzheimer's disease. Cell 169, 1276.e17-1290.e17. doi: 10.1016/j.cell.2017.05.018

Khodanovich, M. Y., Kisel, A. A., Akulov, A. E., Atochin, D. N., Kudabaeva, M. S., Glazacheva, V. Y., et al. (2018). Quantitative assessment of demyelination in ischemic stroke in vivo using macromolecular proton fraction mapping. J. Cereb. Blood Flow Metab. 38, 919-931. doi: 10.1177/0271678x18 755203

Kierdorf, K., Erny, D., Goldmann, T., Sander, V., Schulz, C., Perdiguero, E. G., et al. (2013). Microglia emerge from erythromyeloid precursors via Pu.1- and Irf8-dependent pathways. Nat. Neurosci. 16, 273-280. doi: 10.1038/nn.3318

Kimura, M., Sato, M., Akatsuka, A., Nozawa-Kimura, S., Takahashi, R., Yokoyama, M., et al. (1989). Restoration of myelin formation by a single type of myelin basic protein in transgenic shiverer mice. Proc. Natl. Acad. Sci. US A 86, 5661-5665. doi: 10.1073/pnas.86.14.5661

King, I. L., Dickendesher, T. L., and Segal, B. M. (2009). Circulating Ly-6C ${ }^{+}$ myeloid precursors migrate to the CNS and play a pathogenic role during autoimmune demyelinating disease. Blood 113, 3190-3197. doi: 10.1182/blood2008-07-168575

Kirby, L., Jin, J., Cardona, J. G., Smith, M. D., Martin, K. A., Wang, J., et al. (2018). Oligodendrocyte precursor cells are co-opted by the immune system to cross-present antigen and mediate cytotoxicity. bioRxiv [Preprint]. 461434. doi: 10.1101/461434

Koizumi, S., Shigemoto-Mogami, Y., Nasu-Tada, K., Shinozaki, Y., Ohsawa, K., Tsuda, M., et al. (2007). UDP acting at P2Y6 receptors is a mediator of microglial phagocytosis. Nature 446, 1091-1095. doi: 10.1038/nature05704

Koles, Z. J., and Rasminsky, M. (1972). A computer simulation of conduction in demyelinated nerve fibres. J. Physiol. 227, 351-364. doi: 10.1113/jphysiol.1972. sp010036

Kotter, M. R., Li, W. W., Zhao, C., and Franklin, R. J. (2006). Myelin impairs CNS remyelination by inhibiting oligodendrocyte precursor cell differentiation. J. Neurosci. 26, 328-332. doi: 10.1523/jneurosci.2615-05.2006

Krasemann, S., Madore, C., Cialic, R., Baufeld, C., Calcagno, N., Fatimy El, R., et al. (2017). The TREM2-APOE pathway drives the transcriptional phenotype of dysfunctional microglia in neurodegenerative diseases. Immunity 47, 566.e9-581.e9. doi: 10.1016/j.immuni.2017.08.008

Kuhlmann, T., Ludwin, S., Prat, A., Antel, J., Brück, W., and Lassmann, H. (2017). An updated histological classification system for multiple sclerosis lesions. Acta Neuropathol. 133, 13-24. doi: 10.1007/s00401-016-1653-y

Kuhlmann, T., Miron, V., Cui, Q., Cuo, Q., Wegner, C., Antel, J., et al. (2008). Differentiation block of oligodendroglial progenitor cells as a cause for remyelination failure in chronic multiple sclerosis. Brain 131, 1749-1758. doi: 10.1093/brain/awn096

Kumamaru, H., Saiwai, H., Kobayakawa, K., Kubota, K., Rooijen van, N., Inoue, K., et al. (2012). Liposomal clodronate selectively eliminates microglia from primary astrocyte cultures. J. Neuroinflammation 9:116. doi: 10.1186/17422094-9-116

Lampron, A., Larochelle, A., Laflamme, N., Prefontaine, P., Plante, M. M., Sanchez, M. G., et al. (2015). Inefficient clearance of myelin debris by microglia impairs remyelinating processes. J. Exp. Med. 212, 481-495. doi: 10.1084/jem. 20141656

Lassmann, H., and van Horssen, J. (2016). Oxidative stress and its impact on neurons and glia in multiple sclerosis lesions. Biochim. Biophys. Acta 1862, 506-510. doi: 10.1016/j.bbadis.2015.09.018
Law, M., Saindane, A. M., Ge, Y., Babb, J. S., Johnson, G., Mannon, L. J., et al. (2004). Microvascular abnormality in relapsing-remitting multiple sclerosis: perfusion MR imaging findings in normal-appearing white matter. Radiology 231, 645-652. doi: 10.1148/radiol.2313030996

Lawson, L. J., Perry, V. H., Dri, P., and Gordon, S. (1990). Heterogeneity in the distribution and morphology of microglia in the normal adult mouse brain. Neuroscience 39, 151-170. doi: 10.1016/0306-4522(90)90229-w

Lévesque, S. A., Paré, A., Mailhot, B., Bellver-Landete, V., Kébir, H., Lécuyer, M. A., et al. (2016). Myeloid cell transmigration across the CNS vasculature triggers IL-1 $\beta$-driven neuroinflammation during autoimmune encephalomyelitis in mice. J. Exp. Med. 213, 929-949. doi: 10.1084/jem. 20151437

Levine, J. M., and Reynolds, R. (1999). Activation and proliferation of endogenous oligodendrocyte precursor cells during ethidium bromideinduced demyelination. Exp. Neurol. 160, 333-347. doi: 10.1006/exnr. 1999.7224

Li, C., Zhang, L., Chao, F., Xiao, Q., Luo, Y., and Tang, Y. (2017). Stereological quantification of age-related changes in myelinated fibers of rat white matter. Neuroreport 28, 42-49. doi: 10.1097/wnr.0000000000000706

Liddelow, S. A., and Barres, B. A. (2017). Reactive astrocytes: production, function and therapeutic potential. Immunity 46, 957-967. doi: 10.1016/j.immuni.2017. 06.006

Liddelow, S. A., Guttenplan, K. A., Clarke, L. E., Bennett, F. C., Bohlen, C. J., Schirmer, L., et al. (2017). Neurotoxic reactive astrocytes are induced by activated microglia. Nature 541, 481-487. doi: 10.1038/nature21029

Linton, M. F., Gish, R., Hubl, S. T., Butler, E., Esquivel, C., Bry, W. I., et al. (1991). Phenotypes of apolipoprotein B and apolipoprotein E after liver transplantation. J. Clin. Invest. 88, 270-281. doi: 10.1172/JCI115288

Liu, L., Belkadi, A., Darnall, L., Hu, T., Drescher, C., Cotleur, A. C., et al. (2010). CXCR2-positive neutrophils are essential for cuprizone-induced demyelination: relevance to multiple sclerosis. Nat. Neurosci. 13, 319-326. doi: $10.1038 / \mathrm{nn} .2491$

Liu, A., Li, J., Marin-Husstege, M., Kageyama, R., Fan, Y., Gelinas, C., et al. (2006). A molecular insight of Hes5-dependent inhibition of myelin gene expression: old partners and new players. EMBO J. 25, 4833-4842. doi: 10.1038/sj.emboj. 7601352

Lloyd, A. F., Davies, C. L., Holloway, R. K., Labrak, Y., Ireland, G., Carradori, D., et al. (2019). Central nervous system regeneration is driven by microglia necroptosis and repopulation. Nat. Neurosci. 22, 1046-1052. doi: 10.1038/s41593-019-0418-z

Locatelli, G., Theodorou, D., Kendirli, A., Jordão, M. J. C., Staszewski, O., Phulphagar, K., et al. (2018). Mononuclear phagocytes locally specify and adapt their phenotype in a multiple sclerosis model. Nat. Neurosci. 21, 1196-1208. doi: $10.1038 / \mathrm{s} 41593-018-0212-3$

MacLeod, A. S., and Mansbridge, J. N. (2016). The innate immune system in acute and chronic wounds. Adv. Wound Care 5, 65-78. doi: 10.1089/wound. 2014.0608

Maeda, Y., Solanky, M., Menonna, J., Chapin, J., Li, W., and Dowling, P. (2001). Platelet-derived growth factor- $\alpha$ receptor-positive oligodendroglia are frequent in multiple sclerosis lesions. Ann. Neurol. 49, 776-785. doi: 10.1002/ ana. 1015

Majmundar, A. J., Wong, W. J., and Simon, M. C. (2010). Hypoxia-inducible factors and the response to hypoxic stress. Mol. Cell 40, 294-309. doi: 10.1016/j. molcel.2010.09.022

Mason, J. L., Suzuki, K., Chaplin, D. D., and Matsushima, G. K. (2001). Interleukin-1 $\beta$ promotes repair of the CNS. J. Neurosci. 21, 7046-7052. doi: 10.1523/JNEUROSCI.21-18-07046.2001

Masuda, T., Sankowski, R., Staszewski, O., Böttcher, C., Amann, L., Sagar, et al. (2019). Spatial and temporal heterogeneity of mouse and human microglia at single-cell resolution. Nature 566, 388-392. doi: 10.1038/s41586-019 -0924-x

Mayo, L., Quintana, F. J., and Weiner, H. L. (2012). The innate immune system in demyelinating disease. Immunol. Rev. 248, 170-187. doi: 10.1111/j.1600-065x. 2012.01135.x

McTigue, D. M., Tripathi, R., and Wei, P. (2006). NG2 colocalizes with axons and is expressed by a mixed cell population in spinal cord lesions. J. Neuropathol. Exp. Neurol. 65, 406-420. doi: 10.1097/01.jnen.0000218447. 32320.52 
Mei, F., Lehmann-Horn, K., Shen, Y. A., Rankin, K. A., Stebbins, K. J., Lorrain, D. S., et al. (2016). Accelerated remyelination during inflammatory demyelination prevents axonal loss and improves functional recovery. Elife 5:e18246. doi: 10.7554/elife.18246

Messersmith, D. J., Murtie, J. C., Le, T. Q., Frost, E. E., and Armstrong, R. C. (2000). Fibroblast growth factor 2 (FGF2) and FGF receptor expression in an experimental demyelinating disease with extensive remyelination. J. Neurosci. Res. 62, 241-256. doi: 10.1002/1097-4547(20001015)62:2<241::aid-jnr9>3.0. $\mathrm{co} ; 2-\mathrm{d}$

Micu, I., Plemel, J. R., Caprariello, A. V., Nave, K. A., and Stys, P. K. (2017). Axo-myelinic neurotransmission: a novel mode of cell signalling in the central nervous system. Nat. Rev. Neurosci. 19:58. doi: 10.1038/nrn.2017.128

Mierzwa, A. J., Marion, C. M., Sullivan, G. M., McDaniel, D. P., and Armstrong, R. C. (2015). Components of myelin damage and repair in the progression of white matter pathology after mild traumatic brain injury. J. Neuropathol. Exp. Neurol. 74, 218-232. doi: 10.1097/nen.000000000 0000165

Miron, V. E., Boyd, A., Zhao, J.-W., Yuen, T. J., Ruckh, J. M., Shadrach, J. L., et al. (2013). M2 microglia and macrophages drive oligodendrocyte differentiation during CNS remyelination. Nat. Neurosci. 16, 1211-1218. doi: 10.1038/nn.3469

Mishra, M. K., and Yong, V. W. (2016). Myeloid cells-targets of medication in multiple sclerosis. Nat. Rev. Neurol. 12, 539-551. doi: 10.1038/nrneurol. 2016.110

Mitew, S., Kirkcaldie, M. T., Halliday, G. M., Shepherd, C. E., Vickers, J. C., and Dickson, T. C. (2010). Focal demyelination in Alzheimer's disease and transgenic mouse models. Acta Neuropathol. 119, 567-577. doi: 10.1007/s00401-010-0657-2

Mittelbronn, M., Dietz, K., Schluesener, H. J., and Meyermann, R. (2001). Local distribution of microglia in the normal adult human central nervous system differs by up to one order of magnitude. Acta Neuropathol. 101, 249-255. doi: 10.1007/s004010000284

Miyamoto, A., Wake, H., Ishikawa, A. W., Eto, K., Shibata, K., Murakoshi, H., et al. (2016). Microglia contact induces synapse formation in developing somatosensory cortex. Nat. Commun. 7:12540. doi: 10.1038/ncomms 12540

Molofsky, A. V., and Deneen, B. (2015). Astrocyte development: a guide for the perplexed. Glia 63, 1320-1329. doi: 10.1002/glia.22836

Monk, K. R., Feltri, M. L., and Taveggia, C. (2015). New insights on Schwann cell development. Glia 63, 1376-1393. doi: 10.1002/glia.22852

Monteiro de Castro, G., Deja, N. A., Ma, D., Zhao, C., and Franklin, R. J. (2015). Astrocyte activation via Stat3 signaling determines the balance of oligodendrocyte versus schwann cell remyelination. Am. J. Pathol. 185, 2431-2440. doi: 10.1016/j.ajpath.2015.05.011

Moore, S. A. (2001). Polyunsaturated fatty acid synthesis and release by brainderived cells in vitro. J. Mol. Neurosci. 16, 195-200; discussion 215-221. doi: 10.1385/JMN:16:2-3:195

Moore, C. S., Abdullah, S. L., Brown, A., Arulpragasam, A., and Crocker, S. J. (2011). How factors secreted from astrocytes impact myelin repair. J. Neurosci. Res. 89, 13-21. doi: 10.1002/jnr.22482

Moyon, S., Dubessy, A. L., Aigrot, M. S., Trotter, M., Huang, J. K., Dauphinot, L., et al. (2015). Demyelination causes adult CNS progenitors to revert to an immature state and express immune cues that support their migration. J. Neurosci. 35, 4-20. doi: 10.1523/JNEUROSCI.0849-14.2015

Mozafari, S., Sherafat, M. A., Javan, M., Mirnajafi-Zadeh, J., and Tiraihi, T. (2010). Visual evoked potentials and MBP gene expression imply endogenous myelin repair in adult rat optic nerve and chiasm following local lysolecithin induced demyelination. Brain Res. 1351, 50-56. doi: 10.1016/j.brainres.2010.07.026

Mrdjen, D., Pavlovic, A., Hartmann, F. J., Schreiner, B., Utz, S. G., Leung, B. P., et al. (2018). High-dimensional single-cell mapping of central nervous system immune cells reveals distinct myeloid subsets in health, aging, and disease. Immunity 48, 380.e6-395.e6. doi: 10.1016/j.immuni.2018.01.011

Murtie, J. C., Zhou, Y. X., Le, T. Q., Vana, A. C., and Armstrong, R. C. (2005). PDGF and FGF2 pathways regulate distinct oligodendrocyte lineage responses in experimental demyelination with spontaneous remyelination. Neurobiol. Dis. 19, 171-182. doi: 10.1016/j.nbd.2004.12.006

Nakanishi, M., Niidome, T., Matsuda, S., Akaike, A., Kihara, T., and Sugimoto, H. (2007). Microglia-derived interleukin-6 and leukaemia inhibitory factor promote astrocytic differentiation of neural stem/progenitor cells. Eur. J. Neurosci. 25, 649-658. doi: 10.1111/j.1460-9568.2007.05309.x
Narayanan, V., Cerina, M., Göbel, K., Meuth, P., Herrmann, A. M., FernandezOrth, J., et al. (2018). Impairment of frequency-specific responses associated with altered electrical activity patterns in auditory thalamus following focal and general demyelination. Exp. Neurol. 309, 54-66. doi: 10.1016/j.expneurol.2018. 07.010

Natrajan, M. S., de la Fuente, A. G., Crawford, A. H., Linehan, E., Nuñez, V., Johnson, K. R., et al. (2015). Retinoid X receptor activation reverses age-related deficiencies in myelin debris phagocytosis and remyelination. Brain 138, 3581-3597. doi: 10.1093/brain/awv289

Nieweg, K., Schaller, H., and Pfrieger, F. W. (2009). Marked differences in cholesterol synthesis between neurons and glial cells from postnatal rats. J. Neurochem. 109, 125-134. doi: 10.1111/j.1471-4159.2009.05917.x

Nikic, I., Merkler, D., Sorbara, C., Brinkoetter, M., Kreutzfeldt, M., Bareyre, F. M., et al. (2011). A reversible form of axon damage in experimental autoimmune encephalomyelitis and multiple sclerosis. Nat. Med. 17, 495-499. doi: $10.1038 / \mathrm{nm} .2324$

Nimmerjahn, A., Kirchhoff, F., and Helmchen, F. (2005). Resting microglial cells are highly dynamic surveillants of brain parenchyma in vivo. Science 308, 1314-1318. doi: 10.1126/science.1110647

Niu, J., Tsai, H. H., Hoi, K. K., Huang, N., Yu, G., Kim, K., et al. (2019). Aberrant oligodendroglial-vascular interactions disrupt the bloodbrain barrier, triggering CNS inflammation. Nat. Neurosci. 22, 709-718. doi: 10.1038/s41593-019-0369-4

Olsson, Y. (1974). Mast cells in plaques of multiple sclerosis. Acta Neurol. Scand. 50, 611-618. doi: 10.1111/j.1600-0404.1974.tb02806.x

Paré, A., Mailhot, B., Lévesque, S. A., Juzwik, C., Ignatius Arokia Doss, P. M., Lécuyer, M. A., et al. (2018). IL-1 $\beta$ enables CNS access to CCR2 ${ }^{h i}$ monocytes and the generation of pathogenic cells through GM-CSF released by CNS endothelial cells. Proc. Natl. Acad. Sci. U S A 115, E1194-E1203. doi: 10.1073/pnas.1714948115

Patani, R., Balaratnam, M., Vora, A., and Reynolds, R. (2007). Remyelination can be extensive in multiple sclerosis despite a long disease course. Neuropathol. Appl. Neurobiol. 33, 277-287. doi: 10.1111/j.1365-2990.2007. 00805.x

Patrikios, P., Stadelmann, C., Kutzelnigg, A., Rauschka, H., Schmidbauer, M., Laursen, H., et al. (2006). Remyelination is extensive in a subset of multiple sclerosis patients. Brain 129, 3165-3172. doi: 10.1093/brain/awl217

Plemel, J. R., Keough, M. B., Duncan, G. J., Sparling, J. S., Yong, V. W., Stys, P. K., et al. (2014). Remyelination after spinal cord injury: is it a target for repair? Prog. Neurobiol. 117, 54-72. doi: 10.1016/j.pneurobio.2014.02.006

Plemel, J. R., Liu, W. Q., and Yong, V. W. (2017). Remyelination therapies: a new direction and challenge in multiple sclerosis. Nat. Rev. Drug Discov. 16, 617-634. doi: 10.1038/nrd.2017.115

Plemel, J. R., Manesh, S. B., Sparling, J. S., and Tetzlaff, W. (2013). Myelin inhibits oligodendroglial maturation and regulates oligodendrocytic transcription factor expression. Glia 61, 1471-1487. doi: 10.1002/glia.22535

Plemel, J. R., Michaels, N. J., Weishaupt, N., Caprariello, A. V., Keough, M. B., Rogers, J. A., et al. (2018). Mechanisms of lysophosphatidylcholine-induced demyelination: a primary lipid disrupting myelinopathy. Glia 66, 327-347. doi: 10.1002/glia.23245

Pluvinage, J. V., Haney, M. S., Smith, B. A. H., Sun, J., Iram, T., Bonanno, L., et al. (2019). CD22 blockade restores homeostatic microglial phagocytosis in ageing brains. Nature 568, 187-192. doi: 10.1038/s41586-019-1088-4

Polito, A., and Reynolds, R. (2005). NG2-expressing cells as oligodendrocyte progenitors in the normal and demyelinated adult central nervous system. J. Anat. 207, 707-716. doi: 10.1111/j.1469-7580.2005. 00454.x

Popovich, P. G., Guan, Z., Wei, P., Huitinga, I., van Rooijen, N., and Stokes, B. T. (1999). Depletion of hematogenous macrophages promotes partial hindlimb recovery and neuroanatomical repair after experimental spinal cord injury. Exp. Neurol. 158, 351-365. doi: 10.1006/exnr.1999.7118

Powers, B. E., Lasiene, J., Plemel, J. R., Shupe, L., Perlmutter, S. I., Tetzlaff, W., et al. (2012). Axonal thinning and extensive remyelination without chronic demyelination in spinal injured rats. J. Neurosci. 32, 5120-5125. doi: 10.1523/JNEUROSCI.0002-12.2012

Prineas, J. W., Barnard, R. O., Kwon, E. E., Sharer, L. R., and Cho, E. S. (1993). Multiple sclerosis: remyelination of nascent lesions. Ann. Neurol. 33, 137-151. doi: 10.1002/ana.410330203 
Psachoulia, K., Chamberlain, K. A., Heo, D., Davis, S. E., Paskus, J. D., Nanescu, S. E., et al. (2016). IL4I1 augments CNS remyelination and axonal protection by modulating T cell driven inflammation. Brain 139, 3121-3136. doi: 10.1093/brain/aww254

Pu, A., Stephenson, E. L., and Yong, V. W. (2018). The extracellular matrix: focus on oligodendrocyte biology and targeting CSPGs for remyelination therapies. Glia 66, 1809-1825. doi: 10.1002/glia.23333

Pusic, A. D., Pusic, K. M., Clayton, B. L., and Kraig, R. P. (2014). IFN $\gamma$ stimulated dendritic cell exosomes as a potential therapeutic for remyelination. J. Neuroimmunol. 266, 12-23. doi: 10.1016/j.jneuroim.2013.10.014

Rawji, K. S., Kappen, J., Tang, W., Teo, W., Plemel, J. R., Stys, P. K., et al. (2018). Deficient surveillance and phagocytic activity of myeloid cells within demyelinated lesions in aging mice visualized by ex vivo live multiphoton imaging. J. Neurosci. 38, 1973-1988. doi: 10.1523/JNEUROSCI.2341-17.2018

Redwine, J. M., and Armstrong, R. C. (1998). In vivo proliferation of oligodendrocyte progenitors expressing $\mathrm{PDGF} \alpha \mathrm{R}$ during early remyelination. J. Neurobiol. 37, 413-428. doi: 10.1002/(sici)10974695(19981115)37:3<413::aid-neu7>3.0.co;2-8

Reichert, F., and Rotshenker, S. (2019). Galectin-3 (MAC-2) controls microglia phenotype whether amoeboid and phagocytic or branched and non-phagocytic by regulating the cytoskeleton. Front. Cell. Neurosci. 13:90. doi: 10.3389/fncel. 2019.00090

Richardson, W. D., Young, K. M., Tripathi, R. B., and McKenzie, I. (2011). NG2glia as multipotent neural stem cells: fact or fantasy? Neuron 70, 661-673. doi: 10.1016/j.neuron.2011.05.013

Rivers, L. E., Young, K. M., Rizzi, M., Jamen, F., Psachoulia, K., Wade, A., et al. (2008). PDGFRA/NG2 glia generate myelinating oligodendrocytes and piriform projection neurons in adult mice. Nat. Neurosci. 11, 1392-1401. doi: 10.1038/nn.2220

Rodriguez, J. P., Coulter, M., Miotke, J., Meyer, R. L., Takemaru, K., and Levine, J. M. (2014). Abrogation of $\beta$-catenin signaling in oligodendrocyte precursor cells reduces glial scarring and promotes axon regeneration after CNS injury. J. Neurosci. 34, 10285-10297. doi: 10.1523/JNEUROSCI.491513.2014

Rosenzweig, S., and Carmichael, S. T. (2015). The axon-glia unit in white matter stroke: mechanisms of damage and recovery. Brain Res. 1623, 123-134. doi: 10.1016/j.brainres.2015.02.019

Rothhammer, V., Borucki, D. M., Tjon, E. C., Takenaka, M. C., Chao, C. C., Ardura-Fabregat, A., et al. (2018). Microglial control of astrocytes in response to microbial metabolites. Nature 557, 724-728. doi: 10.1038/s41586-018 $-0119-x$

Ruckh, J. M., Zhao, J. W., Shadrach, J. L., van Wijngaarden, P., Rao, T. N., Wagers, A. J., et al. (2012). Rejuvenation of regeneration in the aging central nervous system. Cell Stem Cell 10, 96-103. doi: 10.1016/j.stem.2011.11.019

Ruddle, N. H., Bergman, C. M., McGrath, K. M., Lingenheld, E. G., Grunnet, M. L., Padula, S. J., et al. (1990). An antibody to lymphotoxin and tumor necrosis factor prevents transfer of experimental allergic encephalomyelitis. J. Exp. Med. 172, 1193-1200. doi: 10.1084/jem.172.4.1193

Saab, A. S., Tzvetavona, I. D., Trevisiol, A., Baltan, S., Dibaj, P., Kusch, K., et al. (2016). Oligodendroglial NMDA receptors regulate glucose import and axonal energy metabolism. Neuron 91, 119-132. doi: 10.1016/j.neuron.2016.05.016

Safaiyan, S., Kannaiyan, N., Snaidero, N., Brioschi, S., Biber, K., Yona, S., et al. (2016). Age-related myelin degradation burdens the clearance function of microglia during aging. Nat. Neurosci. 19, 995-998. doi: 10.1038/nn.4325

Schauf, C. L., and Davis, F. A. (1974). Impulse conduction in multiple sclerosis: a theoretical basis for modification by temperature and pharmacological agents. J. Neurol. Neurosurg. Psychiatry 37, 152-161. doi: 10.1136/jnnp.37.2.152

Schirmer, L., Mobius, W., Zhao, C., Cruz-Herranz, A., Haim Ben, L., Cordano, C., et al. (2018). Oligodendrocyte-encoded Kir4.1 function is required for axonal integrity. Elife 7:e36428. doi: 10.7554/elife.36428

Segel, M., Neumann, B., Hill, M. F. E., Weber, I. P., Viscomi, C., Zhao, C., et al. (2019). Niche stiffness underlies the ageing of central nervous system progenitor cells. Nature doi: 10.1038/s41586-019-1552-1 [Epub ahead of print].

Selmaj, K., Raine, C. S., and Cross, A. H. (1991). Anti-tumor necrosis factor therapy abrogates autoimmune demyelination. Ann. Neurol. 30, 694-700. doi: 10.1002/ana.410300510

Shakhbazau, A., Schenk, G. J., Hay, C., Kawasoe, J., Klaver, R., Yong, V. W., et al. (2016). Demyelination induces transport of ribosome-containing vesicles from glia to axons: evidence from animal models and MS patient brains. Mol. Biol. Rep. 43, 495-507. doi: 10.1007/s11033-016-3990-2

Shen, S., Sandoval, J., Swiss, V. A., Li, J., Dupree, J., Franklin, R. J., et al. (2008). Age-dependent epigenetic control of differentiation inhibitors is critical for remyelination efficiency. Nat. Neurosci. 11, 1024-1034. doi: 10.1038/nn.2172

Sherratt, R. M., Bostock, H., and Sears, T. A. (1980). Effects of 4-aminopyridine on normal and demyelinated mammalian nerve fibres. Nature 283, 570-572. doi: 10.1038/283570a0

Shields, S. A., Gilson, J. M., Blakemore, W. F., and Franklin, R. J. M. (1999) Remyelination occurs as extensively but more slowly in old rats compared to young rats following gliotoxin-induced CNS demyelination. Glia 28, 77-83. doi: 10.1002/(SICI)1098-1136(199910)28:1<77::AID-GLIA9>3.0.CO;2-F

Siebert, J. R., Conta Steencken, A., and Osterhout, D. J. (2014). Chondroitin sulfate proteoglycans in the nervous system: inhibitors to repair. Biomed Res. Int. 2014:845323. doi: 10.1155/2014/845323

Sim, F. J., Zhao, C., Penderis, J., and Franklin, R. J. (2002). The age-related decrease in CNS remyelination efficiency is attributable to an impairment of both oligodendrocyte progenitor recruitment and differentiation. J. Neurosci. 22, 2451-2459. doi: 10.1523/jneurosci.22-07-02451.2002

Skripuletz, T., Hackstette, D., Bauer, K., Gudi, V., Pul, R., Voss, E., et al. (2013). Astrocytes regulate myelin clearance through recruitment of microglia during cuprizone-induced demyelination. Brain 136, 147-167. doi: 10.1093/brain/aws262

Smith, K. J., Blakemore, W. F., and Mcdonald, W. I. (1979). Central remyelination restores secure conduction. Nature 280, 395-396. doi: 10.1038/28 0395a0

Snaidero, N., Möbius, W., Czopka, T., Hekking, L. H., Mathisen, C., Verkleij, D., et al. (2014). Myelin membrane wrapping of CNS axons by PI(3,4,5)P3dependent polarized growth at the inner tongue. Cell 156, 277-290. doi: 10.1016/j.cell.2013.11.044

Sofroniew, M. V., and Vinters, H. V. (2010). Astrocytes: biology and pathology. Acta Neuropathol. 119, 7-35. doi: 10.1007/s00401-009-0619-8

Sosa, R. A., Murphey, C., Ji, N., Cardona, A. E., and Forsthuber, T. G. (2013). The kinetics of myelin antigen uptake by myeloid cells in the central nervous system during experimental autoimmune encephalomyelitis. J. Immunol. 191, 5848-5857. doi: 10.4049/jimmunol.1300771

Steeland, S., Van Ryckeghem, S., Van Imschoot, G., De Rycke, R., Toussaint, W., Vanhoutte, L., et al. (2017). TNFR1 inhibition with a Nanobody protects against EAE development in mice. Sci. Rep. 7:13646. doi: 10.1038/s41598-01713984-y

Stephenson, E. L., Mishra, M. K., Moussienko, D., Laflamme, N., Rivest, S., Ling, C. C., et al. (2018). Chondroitin sulfate proteoglycans as novel drivers of leucocyte infiltration in multiple sclerosis. Brain 141, 1094-1110. doi: 10.1093/brain/awy033

Stephenson, E. L., Zhang, P., Ghorbani, S., Wang, A., Gu, J., Keough, M. B., et al. (2019). Targeting the chondroitin sulfate proteoglycans: evaluating fluorinated glucosamines and xylosides in screens pertinent to multiple sclerosis. ACS Cent. Sci. 5, 1223-1234. doi: 10.1021/acscentsci.9b00327

Stoffels, J. M., de Jonge, J. C., Stancic, M., Nomden, A., van Strien, M. E., Ma, D., et al. (2013). Fibronectin aggregation in multiple sclerosis lesions impairs remyelination. Brain 136, 116-131. doi: 10.1093/brain/aws313

Streit, W. J. (2002). Microglia as neuroprotective, immunocompetent cells of the CNS. Glia 40, 133-139. doi: 10.1002/glia.10154

Syed, Y. A., Baer, A. S., Lubec, G., Hoeger, H., Widhalm, G., and Kotter, M. R. (2008). Inhibition of oligodendrocyte precursor cell differentiation by myelin-associated proteins. Neurosurg. Focus 24:E5. doi: 10.3171/foc/2008/ 24/3-4/e4

Targett, M. P., Sussman, J., Scolding, N., O’Leary, M. T., Compston, D. A., and Blakemore, W. F. (1996). Failure to achieve remyelination of demyelinated rat axons following transplantation of glial cells obtained from the adult human brain. Neuropathol. Appl. Neurobiol. 22, 199-206. doi: 10.1046/j.1365-2990. 1996.4398043.x

Trebst, C., Sørensen, T. L., Kivisäkk, P., Cathcart, M. K., Hesselgesser, J., Horuk, R., et al. (2001). CCR1+/CCR5+ mononuclear phagocytes accumulate in the central nervous system of patients with multiple sclerosis. Am. J. Pathol. 159, 1701-1710. doi: 10.1016/s0002-9440(10)63017-9

Tripathi, R. B., Rivers, L. E., Young, K. M., Jamen, F., and Richardson, W. D. (2010). NG2 glia generate new oligodendrocytes but few astrocytes in a murine 
experimental autoimmune encephalomyelitis model of demyelinating disease. J Neurosci 30, 16383-16390. doi: 10.1523/jneurosci.3411-10.2010

Tsai, H. H., Niu, J., Munji, R., Davalos, D., Chang, J., Zhang, H., et al. (2016). Oligodendrocyte precursors migrate along vasculature in the developing nervous system. Science 351, 379-384. doi: 10.1126/science.aad3839

Ueno, M., Fujita, Y., Tanaka, T., Nakamura, Y., Kikuta, J., Ishii, M., et al. (2013). Layer $\mathrm{V}$ cortical neurons require microglial support for survival during postnatal development. Nat. Neurosci. 16, 543-551. doi: 10.1038/ nn. 3358

Ulanska-Poutanen, J., Mieczkowski, J., Zhao, C., Konarzewska, K., Kaza, B., Pohl, H. B., et al. (2018). Injury-induced perivascular niche supports alternative differentiation of adult rodent CNS progenitor cells. Elife 7:e30325. doi: $10.7554 /$ elife. 30325

van Rooijen, N. (1992). Liposome-mediated elimination of macrophages. Res. Immunol. 143, 215-219. doi: 10.1016/s0923-2494(92)80169-1

Van Rooijen, N., and Sanders, A. (1994). Liposome mediated depletion of macrophages: mechanism of action, preparation of liposomes and applications. J. Immunol. Methods 174, 83-93. doi: 10.1016/0022-1759(94)90012-4

Varga, A. W., Johnson, G., Babb, J. S., Herbert, J., Grossman, R. I., and Inglese, M. (2009). White matter hemodynamic abnormalities precede sub-cortical gray matter changes in multiple sclerosis. J. Neurol. Sci. 282, 28-33. doi: 10.1016/j. jns.2008.12.036

Vogel, D. Y., Vereyken, E. J., Glim, J. E., Heijnen, P. D., Moeton, M., van der Valk, P., et al. (2013). Macrophages in inflammatory multiple sclerosis lesions have an intermediate activation status. J. Neuroinflammation 10:35. doi: 10.1186/1742-2094-10-35

Voronova, A., Yuzwa, S. A., Wang, B. S., Zahr, S., Syal, C., Wang, J., et al. (2017). Migrating interneurons secrete fractalkine to promote oligodendrocyte formation in the developing mammalian brain. Neuron 94, 500.e9-516.e9. doi: 10.1016/j.neuron.2017.04.018

Voss, E. V., Škuljec, J., Gudi, V., Skripuletz, T., Pul, R., Trebst, C., et al. (2012). Characterisation of microglia during de- and remyelination: can they create a repair promoting environment? Neurobiol. Dis. 45, 519-528. doi: 10.1016/j. nbd.2011.09.008

Wang, H., Allen, M. L., Grigg, J. J., Noebels, J. L., and Tempel, B. L. (1995). Hypomyelination alters $\mathrm{K}^{+}$channel expression in mouse mutants shiverer and Trembler. Neuron 15, 1337-1347. doi: 10.1016/0896-6273(95)90012-8

Wang, G. L., Jiang, B. H., Rue, E. A., and Semenza, G. L. (1995). Hypoxia-inducible factor 1 is a basic-helix-loop-helix-PAS heterodimer regulated by cellular O2 tension. Proc. Natl. Acad. Sci. U S A 92, 5510-5514. doi: 10.1073/pnas.92. 12.5510

Wang, H., Kunkel, D. D., Martin, T. M., Schwartzkroin, P. A., and Tempel, B. L. (1993). Heteromultimeric $\mathrm{K}^{+}$channels in terminal and juxtaparanodal regions of neurons. Nature 365, 75-79. doi: 10.1038/365075a0

Watanabe, M., Toyama, Y., and Nishiyama, A. (2002). Differentiation of proliferated NG2-positive glial progenitor cells in a remyelinating lesion. J. Neurosci. Res. 69, 826-836. doi: 10.1002/jnr.10338

Waxman, S. G., and Brill, M. H. (1978). Conduction through demyelinated plaques in multiple sclerosis: computer simulations of facilitation by short internodes. J. Neurol. Neurosurg. Psychiatry 41, 408-416. doi: 10.1136/jnnp.41.5.408

Wilkins, A., Chandran, S., and Compston, A. (2001). A role for oligodendrocytederived IGF-1 in trophic support of cortical neurons. Glia 36, 48-57. doi: $10.1002 /$ glia.1094

Wilkins, A., Majed, H., Layfield, R., Compston, A., and Chandran, S. (2003). Oligodendrocytes promote neuronal survival and axonal length by distinct intracellular mechanisms: a novel role for oligodendrocytederived glial cell line-derived neurotrophic factor. J. Neurosci. 23, 4967-4974. doi: 10.1523/jneurosci.23-12-04967.2003

Wilson, C. M., Gaber, M. W., Sabek, O. M., Zawaski, J. A., and Merchant, T. E. (2009). Radiation-induced astrogliosis and blood-brain barrier damage can be abrogated using anti-TNF treatment. Int. J. Radiat. Oncol. Biol. Phys. 74, 934-941. doi: 10.1016/j.ijrobp.2009.02.035

Witte, M. E., Schumacher, A. M., Mahler, C. F., Bewersdorf, J. P., Lehmitz, J., Scheiter, A., et al. (2019). Calcium influx through plasma-membrane nanoruptures drives axon degeneration in a model of multiple sclerosis. Neuron 101, 615.e5-624.e5. doi: 10.1016/j.neuron.2018.12.023

Wlodarczyk, A., Holtman, I. R., Krueger, M., Yogev, N., Bruttger, J., Khorooshi, R., et al. (2017). A novel microglial subset plays a key role in myelinogenesis in developing brain. EMBO J. 36, 3292-3308. doi: 10.15252/embj.201696056

Wolswijk, G., and Noble, M. (1992). Cooperation between PDGF and FGF converts slowly dividing O-2Aadult progenitor cells to rapidly dividing cells with characteristics of O-2Aperinatal progenitor cells. J. Cell Biol. 118, 889-900. doi: $10.1083 /$ jcb.118.4.889

Yeatman, J. D., Wandell, B. A., and Mezer, A. A. (2014). Lifespan maturation and degeneration of human brain white matter. Nat. Commun. 5:4932. doi: $10.1038 /$ ncomms5932

Yeung, M. S. Y., Djelloul, M., Steiner, E., Bernard, S., Salehpour, M., Possnert, G., et al. (2019). Dynamics of oligodendrocyte generation in multiple sclerosis. Nature 566, 538-542. doi: 10.1038/s41586-018-0842-3

Young, K. M., Psachoulia, K., Tripathi, R. B., Dunn, S. J., Cossell, L., Attwell, D., et al. (2013). Oligodendrocyte dynamics in the healthy adult CNS: evidence for myelin remodeling. Neuron 77, 873-885. doi: 10.1016/j.neuron.2013.01.006

Yousef, H., Czupalla, C. J., Lee, D., Chen, M. B., Burke, A. N., Zera, K. A., et al. (2019). Aged blood impairs hippocampal neural precursor activity and activates microglia via brain endothelial cell VCAM1. Nat. Med. 25, 988-1000. doi: 10.1038/s41591-019-0440-4

Yuen, T. J., Silbereis, J. C., Griveau, A., Chang, S. M., Daneman, R., Fancy, S. P., et al. (2014). Oligodendrocyte-encoded HIF function couples postnatal myelination and white matter angiogenesis. Cell 158, 383-396. doi: 10.1016/j. cell.2014.04.052

Zamanian, J. L., Xu, L., Foo, L. C., Nouri, N., Zhou, L., Giffard, R. G., et al. (2012). Genomic analysis of reactive astrogliosis. J. Neurosci. 32, 6391-6410. doi: 10.1523/JNEUROSCI.6221-11.2012

Zawadzka, M., Rivers, L. E., Fancy, S. P., Zhao, C., Tripathi, R., Jamen, F., et al. (2010). CNS-resident glial progenitor/stem cells produce Schwann cells as well as oligodendrocytes during repair of CNS demyelination. Cell Stem Cell 6, 578-590. doi: 10.1016/j.stem.2010.04.002

Zhan, X., Jickling, G. C., Ander, B. P., Liu, D., Stamova, B., Cox, C., et al. (2014). Myelin injury and degraded myelin vesicles in Alzheimer's disease. Curr. Alzheimer Res. 11, 232-238. doi: 10.2174/1567205011666140131120922

Zhang, Y., Argaw, A. T., Gurfein, B. T., Zameer, A., Snyder, B. J., Ge, C., et al. (2009). Notch1 signaling plays a role in regulating precursor differentiation during CNS remyelination. Proc. Natl. Acad. Sci. U S A 106, 19162-19167. doi: $10.1073 /$ pnas. 0902834106

Zhang, Y., Chen, K., Sloan, S. A., Bennett, M. L., Scholze, A. R., O'Keeffe, S., et al. (2014). An RNA-sequencing transcriptome and splicing database of glia, neurons, and vascular cells of the cerebral cortex. J. Neurosci. 34, 11929-11947. doi: 10.1523/JNEUROSCI.1860-14.2014

Zhao, C., Ma, D., Zawadzka, M., Fancy, S. P., Elis-Williams, L., Bouvier, G., et al. (2015). Sox2 sustains recruitment of oligodendrocyte progenitor cells following CNS demyelination and primes them for differentiation during remyelination. J. Neurosci. 35, 11482-11499. doi: 10.1523/JNEUROSCI.3655-14.2015

Zhou, J., Wu, Y. C., Xiao, B. J., Guo, X. D., Zheng, Q. X., and Wu, B. (2019). Age-related changes in the global DNA methylation profile of oligodendrocyte progenitor cells derived from rat spinal cords. Curr. Med. Sci. 39, 67-74. doi: 10.1007/s11596-019-2001-y

Conflict of Interest: The authors declare that the research was conducted in the absence of any commercial or financial relationships that could be construed as a potential conflict of interest.

Copyright () 2019 Baaklini, Rawji, Duncan, Ho and Plemel. This is an open-access article distributed under the terms of the Creative Commons Attribution License (CC BY). The use, distribution or reproduction in other forums is permitted, provided the original author(s) and the copyright owner(s) are credited and that the original publication in this journal is cited, in accordance with accepted academic practice. No use, distribution or reproduction is permitted which does not comply with these terms. 